\title{
Impact of Post-fault Flux Adaptation on Six-phase Induction Motor Drives with Parallel Converters
}

\author{
I. Gonzalez-Prieto, M. J. Duran, F. Barrero, Senior Member, IEEE, M. Bermudez, H. Guzmán
}

\begin{abstract}
The redundancy of multiphase drives provides an inherent fault-tolerant capability that is appreciated in applications with a complicated corrective maintenance or safety-critical requirements. Fault restrictions however force the system to be reconfigured to operate in a smooth and efficient manner. Previous works have been focused on the optimization of current waveforms to generate an undisturbed operation but still maintaining the pre-fault rated flux settings. This work shows that efficient controllers can improve the post-fault performance in six-phase induction machines supplied by parallelconnected converters if offline optimization is used to obtain a variable reference flux. Theoretical and experimental results confirm that the proposed flux adaptation method provides higher torque/power capability, lower degree of imbalance in the current sharing between windings and efficiency improvement.
\end{abstract}

Index Terms- Fault-tolerant, multiphase induction machine, efficient control, parallel converters.

\section{INTRODUCTION}

$\mathrm{M}$ ultiphase systems have experienced an important evolution in the last decade due to their advantages over conventional three-phase systems [1-3]. Specifically, the enhanced fault tolerance against open-phase faults has promoted the use of multiphase electric drives in a number of applications where the continuous operation becomes a major concern for either security or economic reasons [3]. On the side of security, aerospace or naval applications are good examples of systems where fault tolerance is highly appreciated [4]. Apart from these safety-critical applications, the enhanced reliability also provides economic benefits when the corrective maintenance is complex and faults may result in a long-term shut down of the whole system, as it is the case of offshore wind farms $[5]$.

Manuscript received October 9, 2015; revised December 5, 2015; accepted February 9,2016.

Copyright (c) 2016 IEEE. Personal use of this material is permitted. However, permission to use this material for any other purposes must be obtained from the IEEE by sending a request to pubs-permissions @ ieee.org.

This work was supported by the Spanish Ministry of Science and Innovation under Projects ENE2014-52536-C2-1-R and DPI2013-44278-R, and the Junta de Andalucía under Project P11-TEP-7555.

I. Gonzalez-Prieto, and F. Barrero are with the Department of Electronic Engineering at the University of Seville, Spain, e-mail: igonzalez14@us.es fbarrero@us.es.

M. Bermudez is with the Laboratory of Electrical Engineering and Power Electronics of Lille (L2EP), Arts et Métiers Paris Tech, Lille, France, e-mail: mario.bermudez-guzman@ensam.eu

M.J. Duran and H. Guzman are with the Department of Electrical Engineering at the University of Malaga, Spain, e-mail: mjduran@uma.es hugguzjim@uma.es.
Regardless of the application, the fault-tolerant capability provided by multiphase drives is a desirable feature. However, the continuous operation after the fault occurrence is achieved at the expense of a certain degree of derating. In other words, the integrity of the system in post-fault situation can be only preserved by decreasing the torque/power production [6]. In such scenario, operating in post-fault situation with pre-fault rated flux may result in low torque/power production and unnecessary losses [7]. Previous works have focused on the determination of the current reference waveforms without optimizing the flux settings in post-fault situation [6,8-12], but it is advisable to use an efficient fault-tolerant control in order to minimize the drive derating and reduce the system losses.

The concept of efficient control has been implemented using different strategies [13], and can be classified into search control (SC) [14-20] or loss model control methods (LMC) [7,21-26]. Regardless of the approach, the strategy to improve the efficiency is typically based on decreasing the magnetic flux in the machine at light loads to reduce the losses at the expense of a slower dynamic response. However, extreme minimization of flux level causes higher copper losses, and it is therefore necessary to calculate the optimal value of the magnetic flux to minimize the total losses.

In the case of search control (SC) methods, the input power is measured online and the degree of magnetization in the machine is iteratively changed until the minimal input power is detected. The main advantage of these perturb-andobserve $(\mathrm{P} \& \mathrm{O})$ methods is their insensitivity to machine parameter detuning. On the other hand, the disadvantages are a slow convergence and torque pulsations due to changes in the magnetic flux. To improve the convergence, fuzzy logic can be applied to estimate the optimum step size of the input power and magnetic flux [17-19]. Regarding torque pulsations, feed-forward compensation [19] and the Fibonacci search method have also been suggested to minimize torque ripple [20].

On the other hand, loss model control (LMC) presents higher convergence velocities and lower torque pulsation when compared with SC method. In this case, the optimal flux level is calculated offline from a theoretical model of the system. To construct the model it is necessary to know the machine parameters, and this constitutes the main weakness of the method since it becomes sensitive to parameter detuning. When the theoretical model is simple the optimal flux can be analytically obtained [21], whereas no analytical techniques can be used when the complexity of the model increases [7, 22-26]. 
Regardless of the control strategy, the literature about efficient control for multiphase machines in healthy operation is scarce [14] and only simulation results have been presented in post-fault operation [7]. Multiphase systems possess additional degrees of freedom and faulttolerant operation requires extra constraints. Then, the extension for the multiphase case of other analysis previously applied in three-phase induction machines is far from being trivial.

This work uses an LMC approach for the post-fault flux optimization considering the specific topology of [12]. The optimum flux is obtained offline from a nonlinear optimization process, and the resulting optimal values are included in the fault-tolerant control scheme, bringing some benefits to the performance of the six-phase induction motor drive:

i) Higher post-fault achievable torque/power.

ii) Reduced losses and improved efficiency with an appropriate dynamic response.

iii) Lower imbalance in the current sharing between both sets of three-phase windings.

The paper is organized as follows. First, section II examines the topology under study and its fault-tolerant capability. Then, the nonlinear optimization procedure that provides the optimal flux for different torque conditions is analyzed in section III. In section IV, an efficient control scheme for post-fault operation is proposed, while section $\mathrm{V}$ validates the proposal through experimentation. Finally, the main conclusions are detailed in section VI.

\section{SIX-PHASE ENERGY CONVERSION SYSTEMS WITH PARALLEL CONNECTION}

\section{A. Description of the topology.}

In the last decade, multiphase systems have experienced an important evolution, partly due to the popularization of back-to-back (BTB) voltage source converters (VSCs) and the evolution of microcontrollers. Full-power topologies based on BTB converters have allowed the development of novel and more competitive energy conversion systems [2729]. The decoupling of machine and grid sides through the dc-link provides better low-voltage ride through capability for grid-connected renewable systems, but also offers the possibility to use multiple three-phase windings on the machine-side [12,27-29]. In this scenario the $n$-phase machine is supplied from $k$ VSCs $(n=3 k)$ that can be arranged in different manners. Parallel connection of VSCs connected to a single dc-link has been suggested to diminish the post-fault derating of the system [6] and series connection is claimed to favour the medium-voltage gridside connection because it elevates the dc-link voltage level [30-31]. However, the most simple and popular topology is the use of independent BTB modules connected to the $k$ sets of three-phase windings [27-29]. Fig. 1 depicts this latter topology for the case of a six-phase machine $(k=2)$.
From the fault tolerance point of view, the use of independent BTB modules provides limited fault-tolerant capability (50\% of pre-fault currents). On the other hand multi-MW energy conversion systems typically require more than two machine-side VSCs (e.g. twelve VSCs are used in [28]). In order to increase the current/power capability of the system and simultaneously enhance the fault-tolerant capability, it has been recently proposed the use of six-phase machines fed by four three-phase two-level voltage source converters (VSCs) [11-12]. Namely, each set of three-phase windings is connected to two three-phase VSCs operating in parallel [11-12] (Fig. 1). This topology, and its fault-tolerant efficient control, is considered further on in this work.

For the purpose of the discussion that follows, it is assumed that the set of windings $a_{1} b_{1} c_{1}$ is connected to VSCs $A_{1} B_{1} C_{1}$ and $A_{1}^{\prime} B_{1}^{\prime} C_{1}^{\prime}$ (collectively designated as VSCs1), and the set of windings $a_{2} b_{2} c_{2}$ is connected to VSCs $A_{2} B_{2} C_{2}$ and $A_{2}^{\prime} B_{2}^{\prime} C_{2}^{\prime}$ (collectively designated as VSCs2). Due to the parallel connection, the phase current is shared between the two VSCs, so that each VSC only needs to be sized to take half of the rated phase current. This reduction in the per-VSC-current is adequate in low-voltage high-power drives, where the use of only two VSCs to drive the six-phase machine is not feasible due to the limited ratings of IGBT-based VSCs (typically around $1 \mathrm{MW}$ ). Similarly to the case of three-phase generators, the parallel converters (Fig. 1) are not tolerant to winding open-phase faults but they provide additional fault tolerance against converter faults, which are more common and unpredictable than machine faults [32].

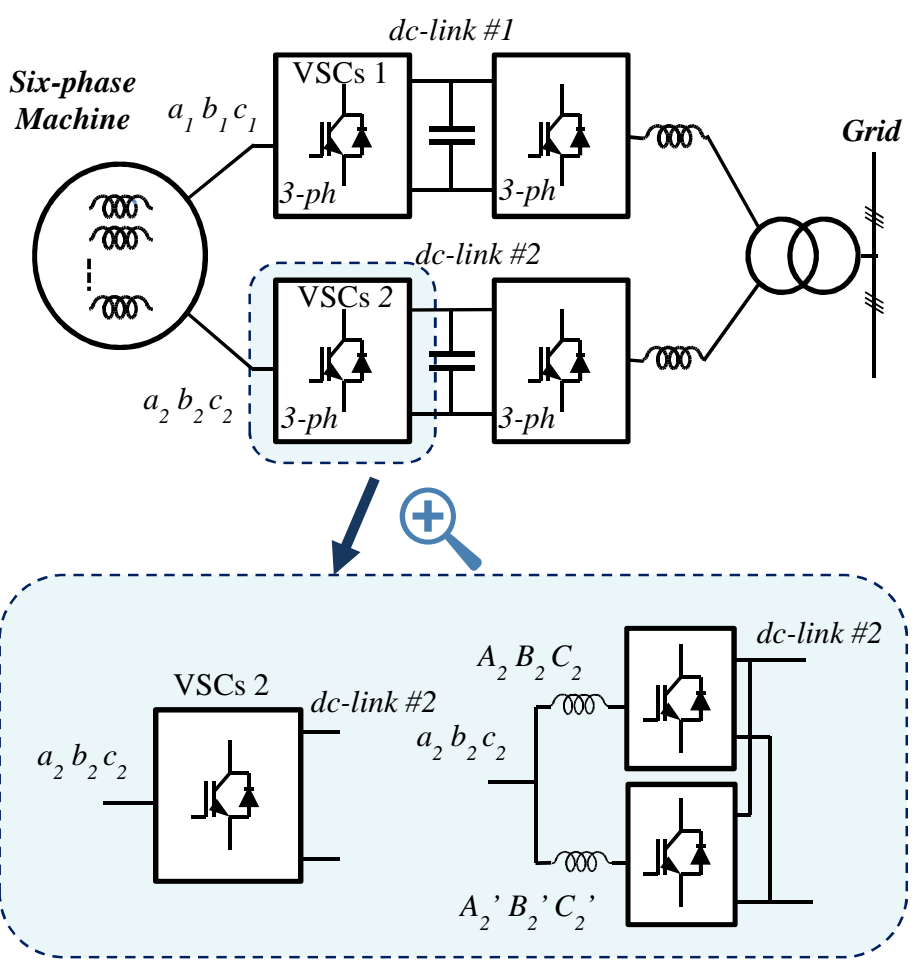

Fig. 1. Multiphase energy conversion system with parallel connection of VSCs. 


\section{B. Model of the six-phase induction machine.}

To complete the description of the six-phase energy conversion system with parallel connection it is necessary to define the model of the machine. The machine employed in this work is an asymmetrical dual three-phase $(k=2)$ induction machine with two isolated neutrals and distributed windings. This multiphase machine is a continuous system described by a set of differential equations obtained using the vector space decomposition (VSD) approach [33] and the power-invariant generalized Clarke transformation [12]:

$$
\begin{aligned}
& v_{\alpha s}=\left(R_{s}+L_{s} \cdot \frac{d}{d t}\right) \cdot i_{\alpha s}+M \cdot \frac{d}{d t} i_{\alpha r} \\
& v_{\beta s}=\left(R_{s}+L_{s} \frac{d}{d t}\right) i_{\beta s}+M \frac{d}{d t} i_{\beta r} \\
& v_{x s}=\left(R_{s}+L_{l s} \frac{d}{d t}\right) i_{x s} \\
& v_{y s}=\left(R_{s}+L_{l s} \frac{d}{d t}\right) i_{y s} \\
& 0=\left(R_{r}+L_{r} \frac{d}{d t}\right) i_{\alpha r}+\omega_{r} L_{r} i_{\beta r}+M \frac{d}{d t} i_{\alpha s}+\omega_{r} M i_{\beta s} \\
& 0=\left(R_{r}+L_{r} \frac{d}{d t}\right) i_{\beta r}-\omega_{r} L_{r} i_{\alpha r}+M \frac{d}{d t} i_{\beta s}-\omega_{r} M i_{\alpha s}
\end{aligned}
$$

where $L_{s}=L_{l s}+3 L_{m s}, L_{r}=L_{l r}+3 L_{m s}, M=3 L_{m s}, \omega_{r}$ is the rotor electrical speed $\left(\omega_{r}=P \cdot \omega, P\right.$ being the pole pair number), indices $s$ and $r$ denote stator and rotor variables and subscripts $l$ and $m$ indicate leakage and magnetizing inductance, respectively. The VSD approach maps the phase components into $\alpha-\beta$ and $x-y$ orthogonal subspaces plus two zero sequence components $\left(0_{+}\right.$and $\left.0_{-}\right)$. While zero sequence currents cannot flow in configurations with two neutrals (and they are consequently omitted in (1)), secondary $x-y$ currents can flow but do not contribute to the torque/flux production in distributed-winding machines with negligible spatial harmonics [3]. They can however cause high copper losses due to the low impedance found in this plane, and for this reason they are regulated to zero in healthy condition. Fault-tolerant operation requires however non-zero $x-y$ current injection in order to comply with the fault restrictions (see section IV for further details). The electromechanical energy conversion process is purely related to the $\alpha-\beta$ plane where the fundamental component is mapped. The model from (1) considers the saturation of the main flux using variable values of magnetizing inductance $L_{m s}$ according to the magnetizing curve of the machine but neglects iron losses for the sake of simplicity because the impact on the optimality of the flux adaptation is low [34].

Since open-phase faults do not affect the electrical machine, the model from (1) can be used both in healthy and faulty modes of operation. Nevertheless, fault tolerance requires additional restrictions to be included in the postfault efficient control as it is described next.

\section{Restrictions in open-phase fault-tolerant operation.}

The fault considered in this work occurs when leg $A_{1}^{\prime}$ of VSCs1 is open-circuited. Open-circuit faults are the most common and unpredictable ones in the converter [32,35] and they are also the most widely studied in literature [3]. A review of IGBT fault diagnostic and protection methods for power converters can be found in [36], while the detection and isolation to safeguard the integrity of the system is addressed in [37-38] for multiphase and multilevel converters, respectively. Other recent works have explored the fault-tolerant capability of multiphase drives against short-circuit faults in the converter [39] or machine [40], but it typically requires a specific design of the drive with a modular structure and dedicated winding arrangement [41].

Due to the parallel connection of the converters $A_{1} B_{1} C_{1}$ and $A_{1}^{\prime} B_{1}^{\prime} C_{1}^{\prime}$, phase- $a_{1}$ is still fed with leg- $A_{1}$ of VSCs 1 , and consequently the current can still flow. However, maximum phase current in phase- $a_{1}$ is now just half of the rated phase current (i.e. $\left.I_{n} / 2\right)$ due to the limitation on the VSCs current rating. If the module of the currents $\left|i_{d q}\right|$ is below $50 \%$ of the rated value of module $\left(\left|i_{d q-\text { rated }}\right|\right)$, this limit is not achieved and the energy conversion system is not affected by the fault. Above this current limit, currents in the faulted set of three-phase windings need to remain balanced and to be equally limited in order to avoid power oscillations:

$i_{a 1} \leq 0.5 I_{n} \cos (\omega t)$

$i_{b 1} \leq 0.5 I_{n} \cos (\omega t-2 \pi / 3)$

$i_{c 1} \leq 0.5 I_{n} \cos (\omega t-4 \pi / 3)$

Since VSCs 2 are healthy, there is no current limit in the other set of three-phase windings and the phase currents can be generally expressed as:

$$
\begin{aligned}
& i_{a 2}=k I_{n} \cos (\omega t-\pi / 6) \\
& i_{b 2}=k I_{n} \cos (\omega t-5 \pi / 6) \\
& i_{c 2}=k I_{n} \cos (\omega t-9 \pi / 6) \\
& 0 \leq k \leq 1
\end{aligned}
$$

where $k$ is a parameter, whose value represents the degree of imbalance in the current sharing between VSCs1 and VSCs2. If $k \leq 0.5$, the solution is trivial and the maximum post-fault $\left|i_{d q}\right|$ is limited to $50 \%$ of the rated value. Higher values of $k$ imply non-zero $x-y$ currents, but also higher output power. The $\alpha-\beta$ and $x-y$ VSD currents can be obtained from (2)-(3) using the Clarke transformation:

$$
\begin{aligned}
& i_{\alpha s}=\sqrt{3} \cdot I_{n} \cdot(0.25+0.5 \cdot k) \cdot \cos (\omega \cdot t) \\
& i_{\beta s}=\sqrt{3} \cdot I_{n} \cdot(0.25+0.5 \cdot k) \cdot \sin (\omega \cdot t) \\
& i_{x s}=\sqrt{3} \cdot I_{n} \cdot(0.25-0.5 \cdot k) \cdot \cos (\omega \cdot t) \\
& i_{y s}=\sqrt{3} \cdot I_{n} \cdot(-0.25+0.5 \cdot k) \cdot \sin (\omega \cdot t)
\end{aligned}
$$

From (4) it can be obtained that $x-y$ currents are related to $\alpha-\beta$ currents by the $k$ factor:

$$
i_{x s}=\frac{0.5-k}{0.5+k} i_{\alpha s} \quad i_{y s}=-\frac{0.5-k}{0.5+k} i_{\beta s}
$$

This means that $x-y$ currents have the same frequency and phase relation as $\alpha-\beta$ currents, with the difference only in their amplitudes. The relationship derived in (5) is important for control purposes and will be used in section IV to build a controller that permits the unbalanced operation defined in (2)-(3) with $k>0.5$. The injection of $x$ - $y$ currents after the fault occurrence affects not only VSCs1 due to current 
restrictions of (2), but also VSCs2 since the currents through the healthy set of three-phase windings need to compensate the limited current capability of the faulty set. Nevertheless, this unbalanced operation can be achieved with different flux settings, and it is still necessary to determine the optimal degree of magnetization in the machine to improve the maximum achievable torque/power and efficiency.

\section{POST-FAULT EFFICIENT CONTROL}

Efficiency in energy conversion systems is a main concern both from economic and environmental points of view. Both SC and LMC techniques have been widely studied for three-phase induction motor drives where flux weakening at light loads in the base speed region is known to improve efficiency at the expense of a slower dynamic response [13]. Aiming to improve the efficiency of the multiphase energy conversion system of Fig. 1, this section studies how to adapt the degree of magnetization in the machine in order to minimize losses. An LMC approach is followed, so it is necessary to make an offline evaluation of the magnetic flux that provides minimum losses for different loading conditions. Compared to similar techniques used in three-phase electrical drives, this study presents the following differences:

$i$. The use of multiphase motor provides additional degrees of freedom (section II.B) to the system complicating the optimization procedure.

ii. The fault-tolerant operation includes additional restrictions (section II.C) in order to maintain the systems ratings.

The degree of magnetization in the machine can be regulated by proper modification of the $d$-current reference settings:

$$
i_{d s}^{*}=a i_{d s-\text { rated }}
$$

where parameter $a$ represents the per unit value of the rated flux used at each operating point. The $q$-current is then calculated to provide the reference torque:

$i_{q s}^{*}=\frac{T_{e}\left(L_{m}+L_{l r}\right)}{P L_{m}^{2} i_{d s}^{*}}$

A problem that is found in fault-tolerant operation when maintaining rated flux $(a=1)$ is that the limited current capability from the restrictions described in section II.C reduces the capability to generate $q$-current. This results in a reduction of the maximum achievable torque/power, as illustrated in Fig. 2a. Operating with reduced flux (point $B$ ) in post-fault condition allows a higher torque/power production than maintaining the pre-fault rated flux (point $A$ ). Apart from this, it is advisable to operate with $a<1$ to reduce losses (Fig. 2b) and improve efficiency in the whole range of operation (Fig. 2c). The losses can be effectively reduced using a proper flux weakening (point $B$ ) instead of keeping a constant flux (point $A$ ). Finally, the degree of imbalance $k$ decreases with the required modulus of the $\alpha-\beta$ current space vector. Since efficient operation results in lower current requirements for the same torque/power, operating with optimal flux leads to a lower imbalance (point $B$ in Fig. 2d) in the current sharing between threephase windings. Nevertheless, these advantages can only be achieved by proper optimization of $a$ in (6), and for this purpose it is necessary to derive the input power consumed by the system.

The rotation speed of the rotor $\left(\omega_{r}\right)$ is an input data, whereas the stator frequency $\left(\omega_{s}\right)$, the angular slip frequency $\left(\omega_{s l}\right)$ and the slip $(s)$ can be obtained from the indirect rotor field oriented control (IRFOC) equations:

$$
\begin{aligned}
& \omega_{s l}=\frac{R_{r} i_{q s}^{* 2}}{\left(L_{m}+L_{l r}\right) a i_{d s-\text { rated }}^{* 2}} \\
& \omega_{s}=\omega_{r} \frac{2 P \pi}{60}+\omega_{s l} \quad|s|=\left|\omega_{s l} / \omega_{s}\right|
\end{aligned}
$$$$
X_{m}=\omega_{s} L_{m} ; \quad X_{l s}=\omega_{s} L_{l s} ; \quad X_{l r}=\omega_{s} L_{l r}
$$

where $X_{l s}$ and $X_{l r}$ are the stator and rotor leakage reactances and $X_{m}$ is the magnetizing reactance.

Considering the VSD model in steady-state conditions, together with the reference settings from (6)-(8), the input power and the losses for any operating point can be calculated as:

$$
\begin{aligned}
& P_{\text {mec }}=T_{e} \omega_{r} \frac{\pi}{30} \\
& P_{\text {out }}=P_{\text {mec }} \\
& P_{\text {out }}=3 I_{n}^{2} R_{r} \frac{s-1}{s} \frac{(0.5 k+0.25)^{2} X_{m}^{2}}{\left(\frac{R_{r}}{s}\right)^{2}+\left(X_{m}+X_{\text {lr }}\right)^{2}} \\
& P_{\text {loss-stator }}=3 I_{n}^{2} R_{s}(0.5 k+0.25)^{2} \\
& P_{\text {loss-rotor }}=3 I_{n}^{2} R_{r} \frac{(0.5 k+0.25)^{2} X_{m}^{2}}{\left(X_{\text {lr }}+X_{m}\right)^{2}+\left(\frac{R_{r}}{s}\right)^{2}} \\
& P_{\text {loss-xy }}=3 I_{n}^{2} R_{s}(0.5 \cdot k-0.25)^{2} \\
& P_{\text {loss }}=P_{\text {loss-stator }}+P_{\text {loss-rotor }}+P_{\text {loss-xy }} \\
& P_{\text {ln }}=P_{\text {out }}+P_{\text {loss }}
\end{aligned}
$$

where $P_{\text {mec }}$ is the mechanical power (neglecting mechanical losses), $P_{\text {out }}$ is the output power provided by the motor (neglecting mechanical losses), $P_{\text {loss }}$ are the copper losses associated to the different currents flowing in the machine and $P_{i n}$ is the input power consumed by the system.

The objective function is to minimize the input power $P_{\text {in }}$ consumed by the system, using an appropriate magnetic flux for each operating point. Once defined the system model, the optimization problem can be written as follows:

$$
\min _{\left(i_{q s}^{*}, a, k, L_{m}\right)}\left\{P_{i n}\right\}
$$

Subject to:

Equations [7 - 10]

$\left|i_{d q}\right|=\sqrt{ }\left(i_{d s}^{* 2}+i_{q s}^{* 2}\right)$

$\left|i_{d q}\right|=\sqrt{3} \cdot I_{n} \cdot(0.5 k+0.25) \quad$ Fault

$0.5 \leq a \leq 1$

restrictions 
Since the system is rather complex, the determination of an analytical solution is not feasible and it is convenient to use methods of nonlinear programming. These optimization techniques are generally included in some commercial software, as it is the case of GAMS [42]. GAMS is widely used in the electrical engineering field and it allows solving nonlinear optimization problems by defining a model of the system, an objective function and an optimization algorithm. Fig. 3 shows a schematic of the optimization problem with the different inputs and outputs of the system. In addition to the current restrictions (2)-(3) and flux limitations (10), the model of the system implemented in GAMS uses the parameters defined in Table 1 and includes the power equations of the six-phase induction machine (9).

The model of (10) is solved in the optimization problem (Fig. 3) for increasing values of $T_{e}^{*}$ and $\omega_{r}^{*}$, within the range $1.6<T_{e}^{*}<3.1 \mathrm{Nm}$ and $100<\omega_{r}^{*}<900 \mathrm{rpm}$. These values match a range from $I_{n} / 2$ to $I_{n}$ of $i_{a 2} i_{b 2} i_{c 2}$ in postfault situation. The optimization procedure performed with GAMS provides the optimal $a$ and $k$ values for different input $\omega_{r}^{*}$ and $T_{e}^{*}$ values. The degree of imbalance $k$ and the optimum magnetic flux $a$ are independent of the speed but present a linear and quadratic relation with the input torque, respectively (Fig. 4). This quadratic relation can be approximated by (torque is given in $\mathrm{Nm}$ ):

$a^{*}=-0.0294 \cdot T_{e}^{* 2}+0.2668 \cdot T_{e}^{*}+0.334$

and it will be used in the post-fault control which is presented in the next section.

It must be noted that the LMC is a model-dependent approach and consequently any mismatch in the parameters or inaccuracy in the model affects to some extent the optimization process. For the sake of example, variations in the stator resistance due to thermal effects modify the degree of imbalance $k$ (Fig. 4a) and the optimum flux $a$ (Fig. 4b) that are obtained from GAMS in the optimization process. Similarly, including the iron losses into the machine model provides higher accuracy but the impact on the optimality is low (see Fig. 4a). For the purpose of highlighting the impact of the flux adaptation on the post-fault performance of sixphase induction motor drives, this work assumes constant parameters and null core losses (see section II.B).

\section{IV.PROPOSED FAULT-TOLERANT EFFICIENT CONTROLLER}

\section{A. Control structure.}

The structure of the pre-fault control strategy is shown in Fig. 5. The scheme is an indirect rotor field oriented control (IRFOC) with an outer speed loop and inner current loops for $d-q$ and $x-y$ currents. Only four phase currents $\left(i_{a 1}, i_{b 1}\right.$, $i_{a 2}$ and $i_{b 2}$ ) need to be measured because the remaining phase currents can be obtained from the condition of having two isolated neutral points. Measured phase currents are converted into $\alpha-\beta$ currents using the Clarke transformation [12] and $d-q$ currents are obtained from the rotation of $\alpha-\beta$ currents in the forward (synchronous) direction using the Park transformation:
$[D]=\left[\begin{array}{cc}\cos \theta_{s} & \sin \theta_{s} \\ -\sin \theta_{s} & \cos \theta_{s}\end{array}\right]$

The angle $\theta_{s}$ of the rotating reference frame is obtained from the measured speed $\omega_{r}$ and the estimated slip:

$\theta_{s}=\int\left(\frac{i_{q s}^{*}}{T_{r} i_{d s}^{*}}+P \cdot \omega_{r}\right) d t$

where $T_{r}$ is the rotor time constant.

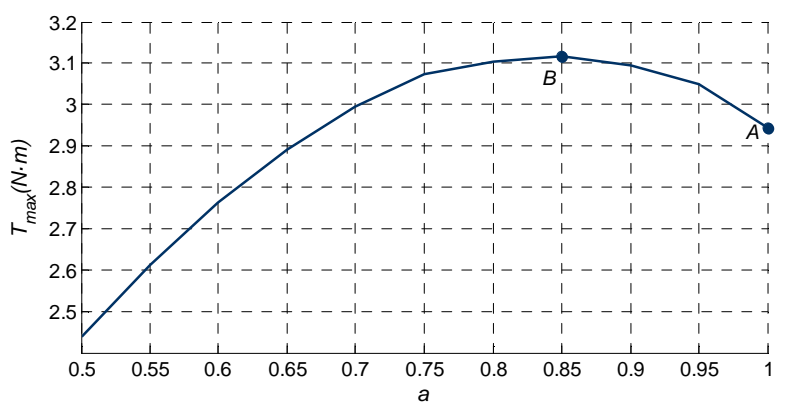

(a)

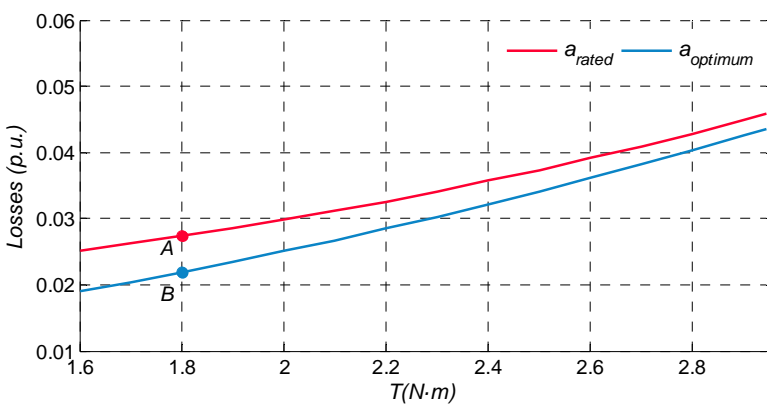

(b)

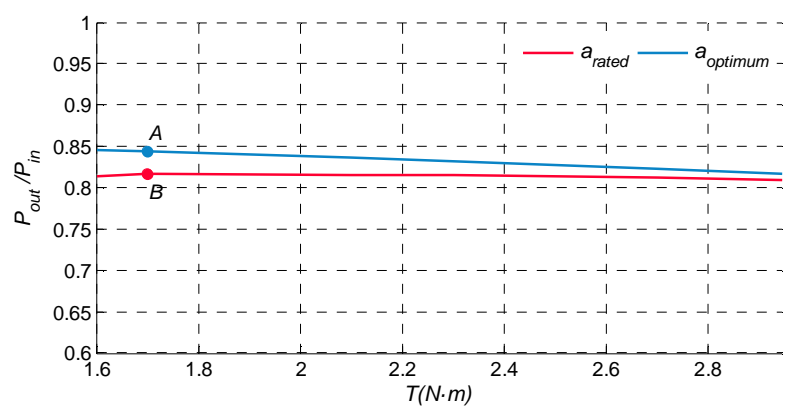

(c)

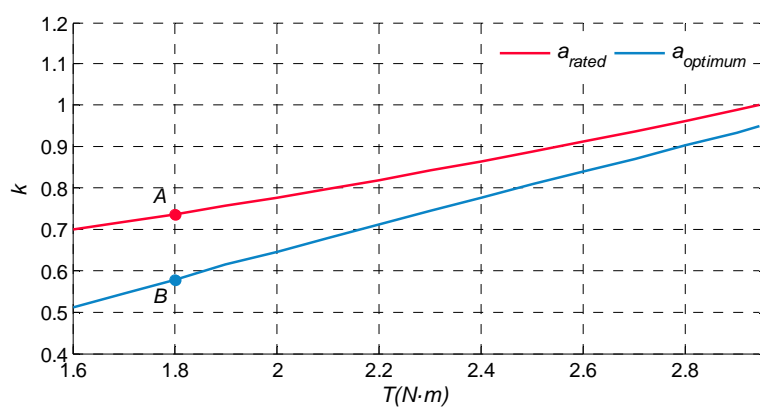

(d)

Fig. 1. Performance comparison with rated flux (point $A$ ) and optimum flux (point $B$ ) obtained in the optimization procedure: a) Maximum torque versus degree of magnetization of the machine, b) losses versus load torque, c) efficiency versus load torque and d) imbalance degree versus load torque 


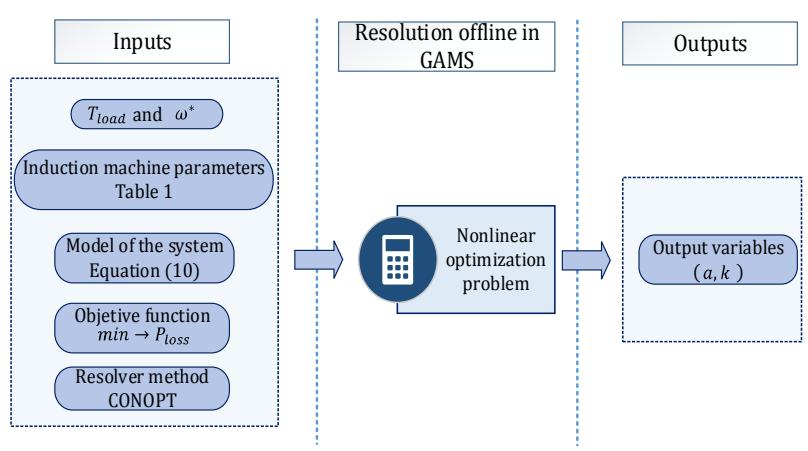

Fig. 3. Schematic of the nonlinear optimization problem

The machine in pre-fault situation is fluxed by setting a value of $i_{d s}^{*}$ that corresponds to the rated flux of the machine, while the torque is regulated by an outer speed control loop that provides its reference. The reference of the quadrature current $i_{q s}^{*}$ can be obtained directly from equation (7) and the reference values of $i_{d s}^{*}$ and $T_{e}^{*}$ (Fig. 5). The output of the $d-q$ current controllers and the decoupling terms $e_{d s}^{*}$ and $e_{q s}^{*}$ [12] provide the reference voltages $v_{d s}^{*}$ and $v_{q s}^{*}$. The second inner current control loop corresponds to the $x-y$ current components. If the $x-y$ control is performed in the stationary reference frame, as it is a common practice in multiphase drives in healthy operation [2], it is necessary to regulate sinusoidal currents and the limited bandwidth of PI controllers will result in a poor performance [3]. For the purpose of regulating non constant $x-y$ currents it has been recently suggested the use of dual PI or resonant controllers $[6,10-11]$; this however complicates to some extent the controller structure and tuning. Fortunately, in this case it is possible to perform the control in a reference frame where $x-y$ currents become constant. It can be noted from (5) that the required $x$-current is proportional to $\alpha$-current while the required $y$-current is inversely proportional to the $\beta$-current. This implies that the $\alpha-\beta$ current vector rotates in synchronous direction whereas the $x-y$ current vector rotates in anti-synchronous direction. It follows that the rotation of $x-y$ currents in backwards direction using the inverse of the Park transformation $[D]^{-1}$ leads to $x-y$ currents (termed $x^{\prime}-y^{\prime}$ in the rotating reference frame, see [43] for further details) becoming proportional to $d$ - $q$ currents:

$$
i_{x s}^{\prime *}=\frac{0.5-k}{0.5+k} \cdot i_{d s}^{*} \quad i_{y s}^{\prime *}=-\frac{0.5-k}{0.5+k} \cdot i_{q s}^{*}
$$

The use of resonant controllers (PR), which is a common procedure in fault-tolerant control schemes with timevarying $x-y$ current references $[8,43]$, is then not necessary.

\section{B. Calculation of post-fault flux and current references.}

The aim in post-fault situation is to drive the machine ensuring that the currents in the faulted VSCs1 are below half the rated value $\left(\max \left|i_{a 1 b 1 c 1}\right| \leq I_{n} / 2\right)$, trying to operate with maximum efficiency. These targets can be achieved by using an appropriate degree of magnetization in the electrical machine and a suitable injection of $x-y$ currents.
The degree of magnetization can be modified including (11) into the control scheme in order to calculate the new reference value $i_{d s}^{*}$ in post-fault situation, as shown in the feedback FB2-b of Fig. 5. The use of an optimized degree of magnetization reduces the required $\left|i_{d q}\right|$ current needed to provide the same reference value of $T_{e}^{*}$ and, consequently, the losses are reduced. This efficient control scheme (termed EIRFOC in what follows) will also allow reduce the losses caused by the injection of $x-y$ currents and the degree of imbalance $k$.

As for the $x-y$ current references, it is necessary to use a controller that injects currents only when it is truly necessary. In the low-torque region, the limit of VSCs1 is not reached and the machine can be symmetrically operated as in pre-fault situation (Fig. 5 with FB1-a). However, when the torque is such that the currents in VSCs1 reach the postfault limit $\left(\max \left|i_{a 1 b 1 c 1}\right|=I_{n} / 2\right)$ for $k=0.5$, the system can no longer increase the generated torque/power unless some imbalance in the power sharing of VSCs1 and VSCs2

\section{TABLE 1. MACHINE PARAMETERS}

\begin{tabular}{c} 
Machine parameters \\
\hline$R_{s}=4.2 \Omega, R_{r}=2 \Omega, P=3$, \\
$L_{l s}=0.0042 H, L_{l r}=0.055 H$, \\
$L_{m}=-0.0482 \cdot i_{d s}^{* 2}+0.0453 \cdot i_{d s}^{*}+0.0415 H$ \\
$\left|I_{n}\right|=2 A, i_{d, \text { rated }}=1.815 A,\left|i_{d q-\text { rated }}\right|=3.45 \mathrm{~A}$ \\
\hline
\end{tabular}

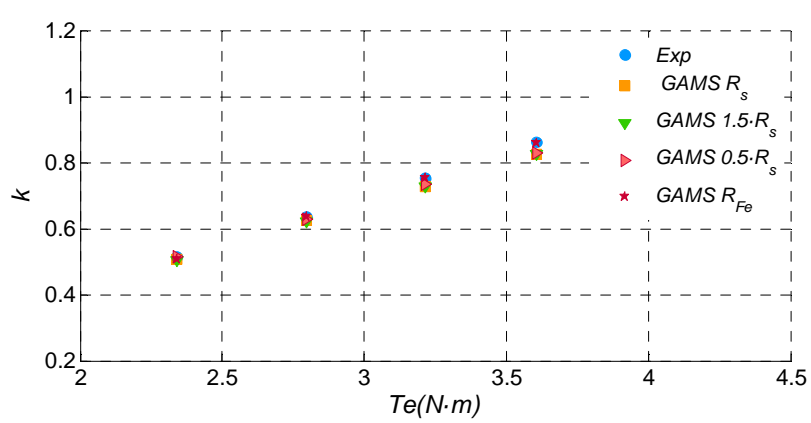

(a)

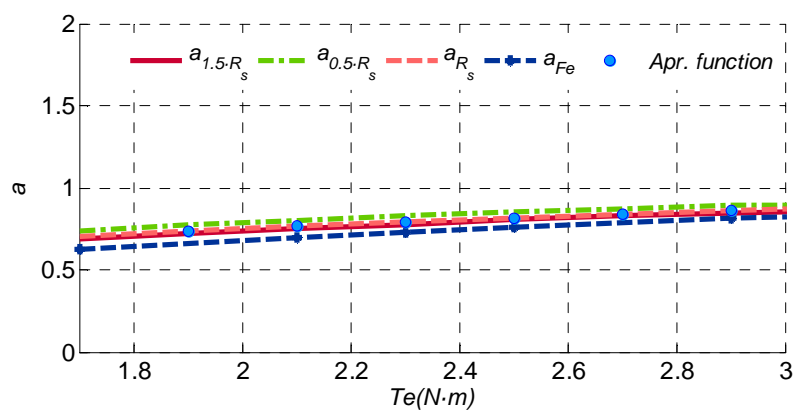

(b)

Fig. 4. Optimal values of $k$ and $a$ for increasing value of the load torque $T_{e}$ : experimental values and theoretical calculation from software GAMS. The optimized results from GAMS are obtained with stator resistance variation $( \pm 50 \%)$ and consideration of the core losses $\left(P_{F e}\right)$. 


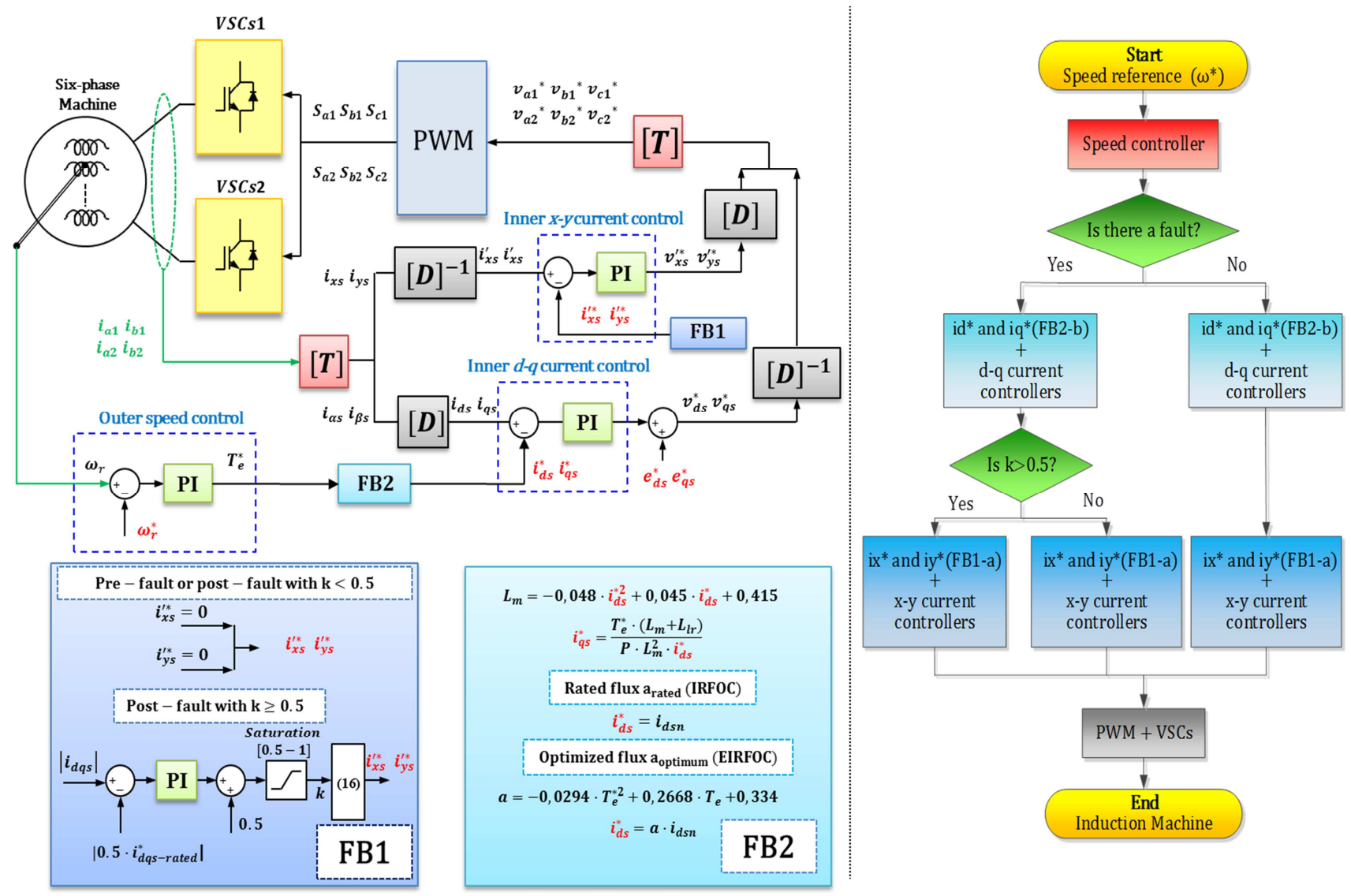

Fig. 5. Field oriented control of the six-phase induction motor drive shown in Fig. 1, including synchronous $d$ - $q$ current control and antisynchronous $x-y$ current control (left). Standard IRFOC is implemented setting rated flux $a_{\text {rated }}$ in FB2-a while efficient field oriented control (EIRFOC) sets the optimized flux $a_{\text {optimum }}$ in FB2-b. Pre-fault or post-fault with $k<0.5$ situations sets null $x$ - $y$ currents in FB1-a, whereas the post-fault control with $k \geq 0.5$ activates the current imbalance controller in FB1-b. Applies to the case of paralleled converters for each three-phase winding at the machine's side.

is permitted. At this moment, the controller of FB1-b in Fig. 5 is activated. This controller is used to provide variable $x-y$ current injection (i.e. variable $k$ ) to generate only the minimum degree of imbalance that is required to comply with current limits. The controller that regulates the imbalance is an anti-wind-up proportional-integral (PI) whose input and output are the excess above half the rated value of the modulus of $d-q$ currents and the $k$ parameter, respectively. The flowchart included on the right hand side of Fig. 5 specifies the conditions for the $d$ - $q$ current settings (FB2-1 or FB-2b) and $x$ - $y$ current settings (FB1-a or FB1-b), according to the fault state and operating point.

\section{IV.EXPERIMENTAL RESULTS.}

\section{A. Test Bench.}

A three-phase induction machine has been rewound to obtain an asymmetrical six-phase induction machine whose electrical parameters have been determined using conventional AC-time domain experiments and stand-still with inverter supply test [44-45] (see obtained results in Table 1). The six-phase machine is driven by conventional three-phase power converters from Semikron (SKS22F modules) that correspond to VSCs1 and VSCs2 in Fig. 1. The control actions are performed by a TI TMS320F28335 digital signal processor. This control unit is programmed through JTAG and TI proprietary software Code Composer Studio. Current and speed measurements are taken with four hall-effect LEM LAH 25-NP sensors (with an accuracy of the $\pm 0,5 \%$ ) and a GHM510296R/2500 digital encoder, respectively. The load torque is provided by a DC-machine whose armature is connected to a variable resistiveinductive load. The full scheme of the test bench is depicted in Fig. 6.

\section{B. Experimental results.}

Different experimental tests have been performed setting a rated $d$-current of $1.815 \mathrm{~A}$, a rated $q$-current of $2.934 \mathrm{~A}$, a switching frequency of $10 \mathrm{kHz}$ and dc-link voltages of $V_{d c 1}=V_{d c 2}=300 \mathrm{~V}$. The threshold for the activation of the controller in FB1-b of Fig. 5 is set to $\left|i_{d q s}\right|=1.720 \mathrm{~A}$, which corresponds to half the rated value. To verify the improvement of the efficient control in post-fault situation, the same tests are done both with standard IRFOC and constant rated flux (FB2-a in Fig. 5) and with proposed EIRFOC and optimum flux (FB2-b in Fig. 5). 


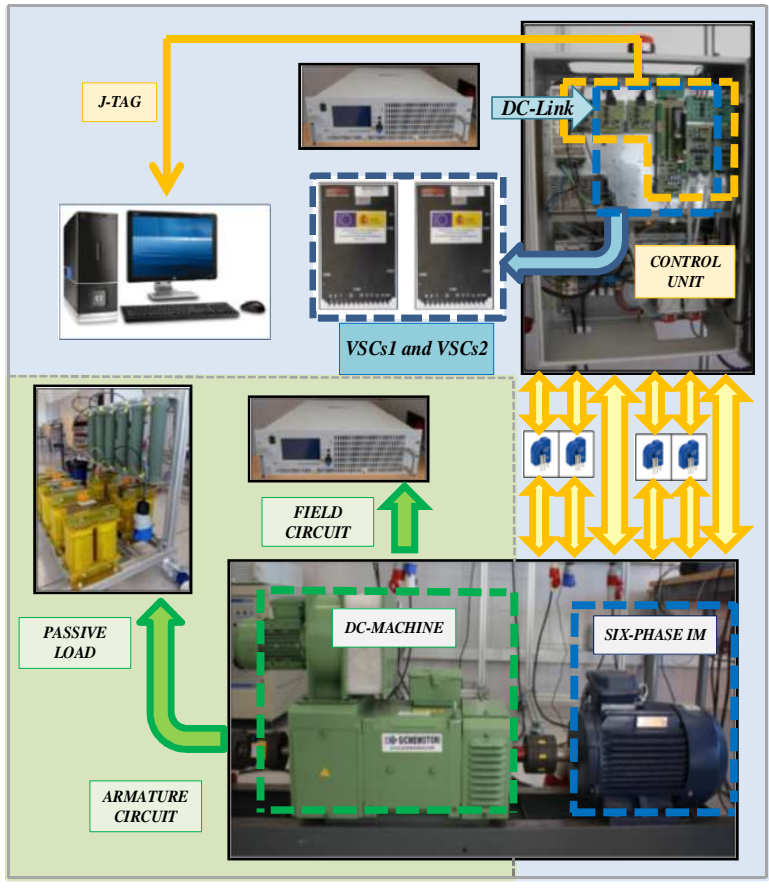

Fig. 6. Test bench used for the experimental results.

First, the transition from pre- to post-fault situations using standard IRFOC (Fig. 7) and EIRFOC (Fig. 8) control methods is studied. From $t=0$ to $5 \mathrm{~s}$ the machine is operated with rated flux at $500 \mathrm{rpm}$ and $2.35 \mathrm{Nm}$ in pre-fault situation. Results confirm that the motor speed is satisfactorily regulated to $500 \mathrm{rpm}$ (Figs. 7a and 8a) with $d$ and $q$ currents of $1.815 \mathrm{~A}$ and $1.4 \mathrm{~A}$ (Figs. $7 \mathrm{~b}$ and $8 \mathrm{~b}$ ), respectively. Since the system is still healthy, the drive is operated in balanced mode with $k=0.5$ (Figs. 7c and 8c) and null $x-y$ currents (Figs. $7 \mathrm{~d}$ and $8 \mathrm{~d}$ ), according to the references set in FB1-b of Fig. 5. At $t=5 \mathrm{~s}$, an open-phase fault is forced in leg $A_{1}^{\prime}$ and the currents in the first set of three-phase windings need to be limited by (2) to half the rated value. After the fault occurrence it is necessary to detect and identify the fault, and this is typically carried out using fault indices that are based on current measurements. Three-phase methods can be used for this purpose (e.g. those based on negative-sequence or zero-sequence currents/voltages [46-47]) but it is also possible to use the additional degrees of freedom existing in multiphase drives to detect the fault based on the evolution of $x-y$ currents [48]. This work however focuses on the post-fault control with flux adaptation and the system is instantaneously reconfigured (neglecting the fault detection delay). At this moment the post-fault $x-y$ current references are no longer set to zero, but obtained from the controller shown in FB1-b of Fig. 5.

When the IRFOC maintains the rated flux reference after the fault (Fig. 7), the $d-q$ currents maintain the same prefault values, with no appreciable impact on the motor speed or $d-q$ current tracking. This smooth transition proves that the system can withstand the fault with no disturbance either in the torque or the speed. However, since the modulus of the $d-q$ currents is over the threshold value ( $\left.\left|i_{d q s}\right|=1.72 \mathrm{~A}\right)$, it is not possible to operate the system in balanced mode after the fault without violating the limits set in (2). For this reason the controller in FB1-b of Fig. 5 is activated and the motor is driven with some degree of current imbalance after the fault occurrence, as it is illustrated in Fig. 7c with values of $k>0.5$. This imbalance in turn implies that the $x$ $y$ currents are no longer zero, as indicated in (14) and shown in Fig. 7d.

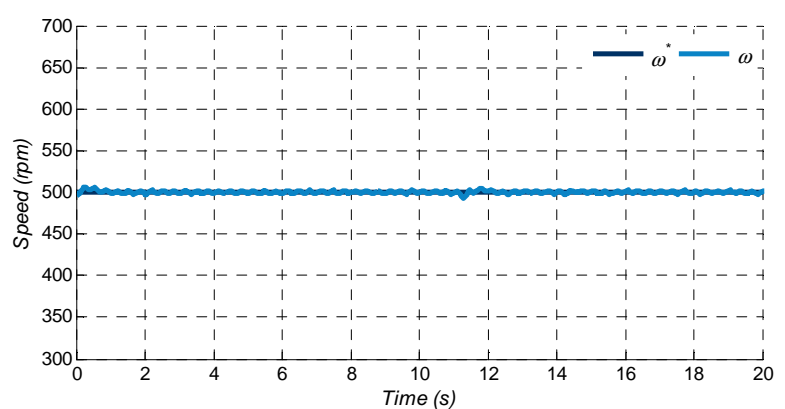

(a)

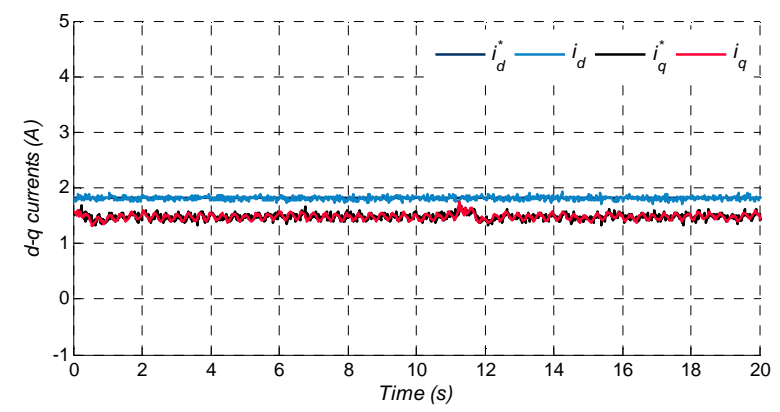

(b)

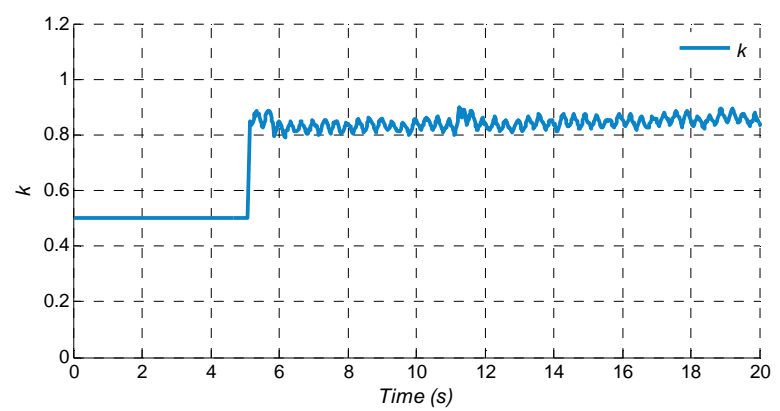

(c)

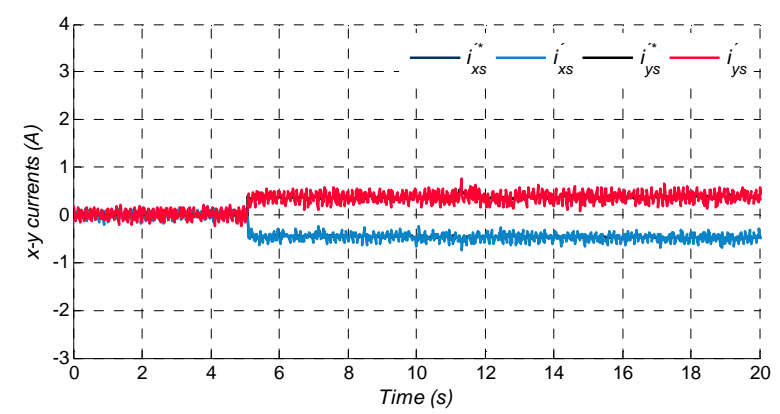

(d)

Fig. 7. Obtained experimental results in a pre- to post-fault transition at $500 \mathrm{rpm}$ using IRFOC. From top to bottom: motor speed, $\boldsymbol{d}$ - $\boldsymbol{q}$ currents, imbalance degree $\boldsymbol{k}$ and $\boldsymbol{x}^{\prime}-\boldsymbol{y}^{\prime}$ currents. 
Alternatively, when the EIRFOC is activated after the fault occurrence (Fig. 8), the $d$-current reference is decreased to the optimum value obtained from equation (11) included in the control scheme of Fig. 5 with FB2b, allowing higher $q$-current (Fig. 8b). Although the load torque is the same, the modulus of the $d-q$ currents is lower with EIRFOC providing lower values of $k$ (Fig. 8c) and $x-y$ currents (Fig. 8d). The injection of the $x-y$ currents leads to the desired unbalanced operation (Fig. 8e) and keeps phase currents of the faulty set within the limits (Fig. 8f). Similarly to the case with the IRFOC strategy, the system can withstand the fault and the transitions from pre- to post-fault operation is smooth, with no undershoot of the speed/torque. However, since the same torque is generated with lower current values, the system losses are reduced (Fig. 9). The same conclusions apply if the switching frequency is reduced, as it is mandatory in high-power energy conversion systems. It is shown in Fig. 10 that operating at $4 \mathrm{kHz}$ increases the current ripple in the $x-y$ plane but the results are mostly similar to those in Fig. 8. This experimental test confirms that EIRFOC allows the operation with lower degree of imbalance (as shown in Fig. 2d) and lower losses (as shown in Fig. 2b), thus confirming the benefit ii) listed in the introduction section. It is important to highlight that lower values of $k$ are specially appreciated in series-

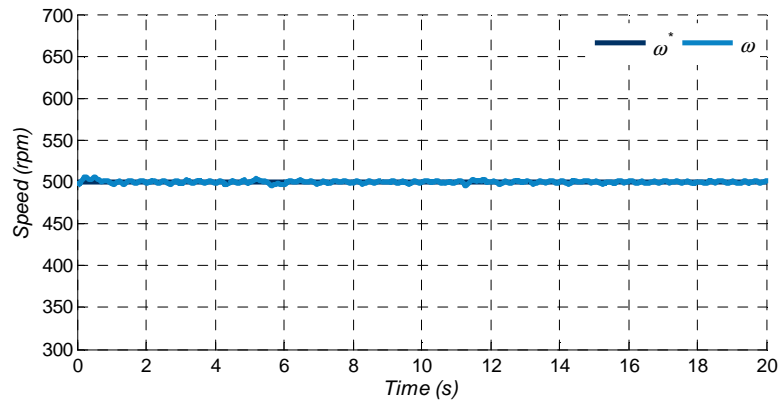

(a)

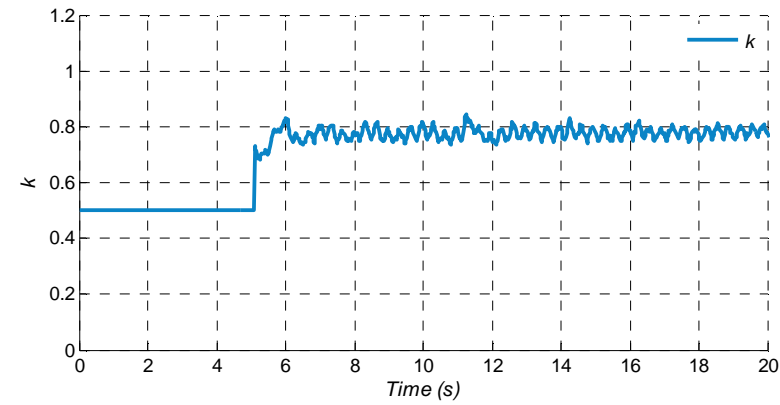

(c)

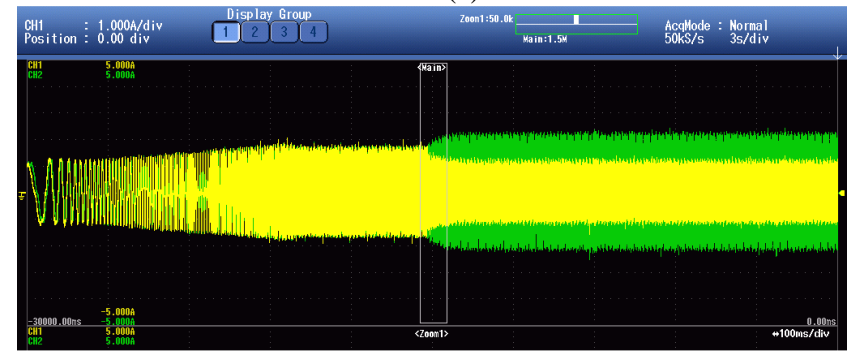

(e) connected topologies [30-31] because higher imbalance in the current sharing complicates the dc-link voltage balancing task. Needless to say that lower losses are always beneficial and lead to better system efficiency.

A second test is performed to verify the post-fault transient operation, again using IRFOC (Fig. 11) and EIRFOC (Fig. 12), according to the control schemes depicted in FB2-a and FB2-b of Fig. 5, respectively. The fault occurs at $t=5 \mathrm{~s}$, and the speed reference is changed at this time from 300 to $500 \mathrm{rpm}$ following a ramp. Since the load torque is provided by a dc-machine whose power/torque is proportional to the square of the speed, the acceleration also implies a load torque increment.

IRFOC and EIRFOC methods are able to satisfactorily regulate the speed (Fig. 11a and Fig. 12a). In the case of IRFOC, the torque change has no effect on the $d$-current, as expected, whereas the $q$-current varies with the increasing values of the torque (Fig. 11b). However, both $d$ - and $q$ currents change with the value of $T_{e}^{*}$ when the EIRFOC is activated after the fault occurrence (Fig. 12b). The $d$-current is modified to adapt the flux to the load torque, according to (11), whereas the $q$-current is obtained from the reference speed ramp.

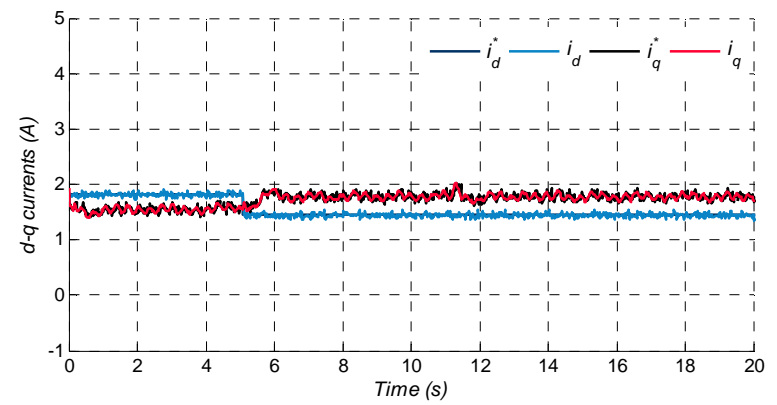

(b)

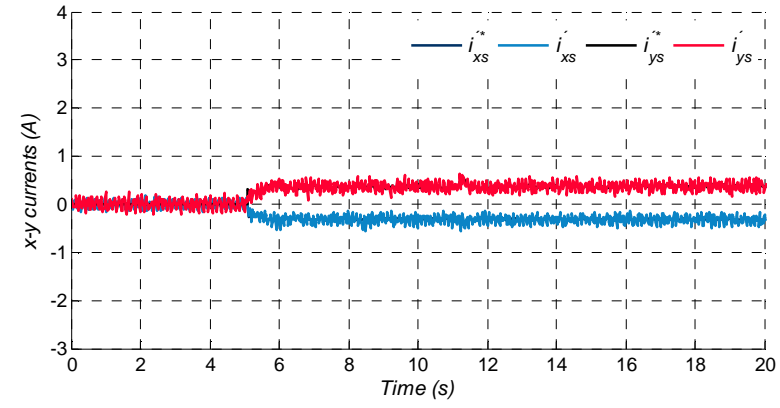

(d)

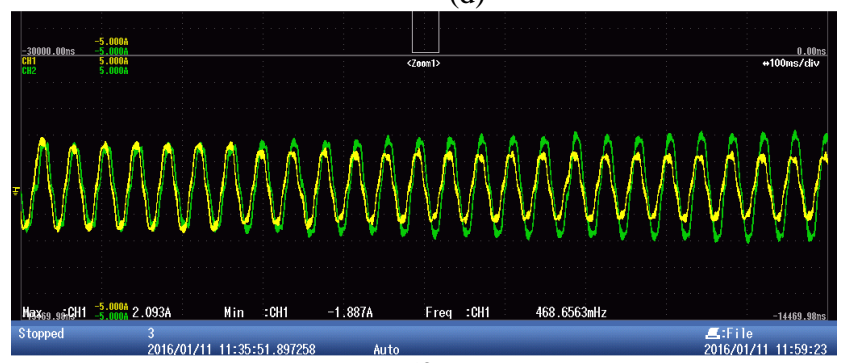

(f)

Fig. 8. Experimental results in a pre- to post-fault transition at $500 \mathrm{rpm}$ with EIRFOC. From left to right and from top to bottom: motor speed, $\boldsymbol{d}-\boldsymbol{q}$ currents, imbalance degree $\boldsymbol{k}$ and $\boldsymbol{x}^{\prime}-\boldsymbol{y}^{\prime}$ currents, scope image of the phase currents during the transient and zoom of the scope. 


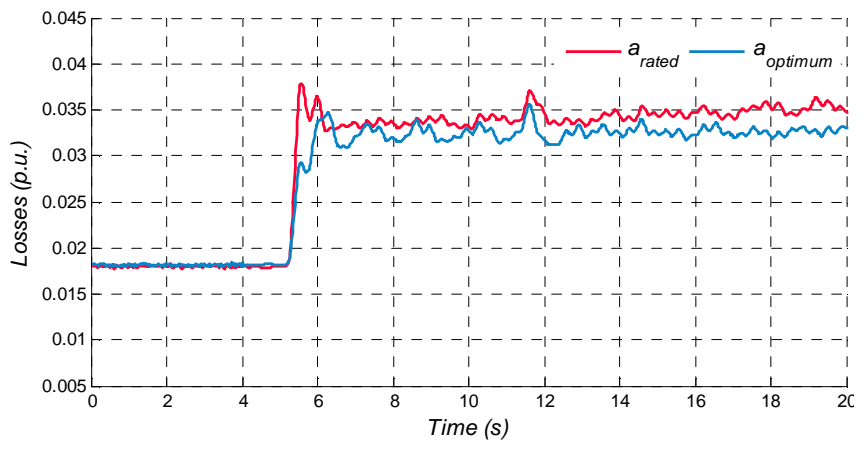

Fig. 9. Motor losses in a pre- to post-fault transition at $500 \mathrm{rpm}$ with IRFOC (red trace) and EIRFOC (blue trace) methods

The $x^{\prime}-y^{\prime}$ current references are given by the controller detailed in FB1-b of Fig. 5, increasing their values after the fault in order to comply with the fault requirements and in accordance with [12]. While standard IRFOC modifies the $x^{\prime}-y^{\prime}$ currents as a function of the imbalance, EIRFOC also considers variations of the $d-q$ currents according to (14). The degree of imbalance $k$ is depicted for IRFOC and EIRFOC in Fig. 11c and 12c, respectively, and Fig. 13 compares the values of $k$ for both strategies in the same figure. As expected, a lower imbalance is needed when the post-fault flux is adapted, thus confirming the benefit iii) listed in the introduction section. Moreover, the time that this variable is saturated at $k=1$ when the change of torque and speed occurs is also lower with the proposed efficient controller. The results obtained in this test confirm a satisfactory transition from pre- to post-fault situations, an improved steady-state performance and a satisfactory dynamic response of the proposed controller in FB2-b of Fig. 5 with optimized flux, being very similar to the controller of FB2-a with rated flux. As indicated in the benefit $i$ ) listed in the introduction section, the performance improvements are obtained retaining a good dynamic response.

A third test is finally performed to verify that operating with an optimized flux leads to higher post-fault achievable torque/power, as previously indicated in Fig. 2a. In this test the machine is operated at $800 \mathrm{rpm}$ and the fault is provoked at $t=5 \mathrm{~s}$ both using IRFOC (Fig. 14) and EIRFOC (Fig. 15). When the IRFOC is used, the load torque is such that the degree of imbalance $k$ is increased up to 1 , where it gets saturated (Fig. 14c). Operating with $k=1$ implies that the drive has reached the post-fault limits (rated and half-rated currents in windings $a_{1} b_{1} c_{1}$ and $a_{2} b_{2} c_{2}$, respectively) and it can no longer maintain the speed at $800 \mathrm{rpm}$ (Fig. 14a). This decrease in the motor speed is obtained because the $d$ current maintains its pre-fault rated value (Fig. 14b). Even though $x-y$ currents are increased after the fault (Fig. 14d) to provoke an imbalance in the current sharing, the capability to generate torque is not sufficient and the speed is reduced. On the contrary, when EIRFOC is activated it is possible to generate a higher torque without exceeding the current limits. The degree of imbalance $k$ is kept below 1 after the fault occurrence (Fig. 15c) and this non-saturated value allows generating the required torque and maintaining the speed at $800 \mathrm{rpm}$ in post-fault situation (Fig. 15a). Consequently, apart from the efficiency improvement and lower degree of imbalance previously shown (Fig. 9 and 13, respectively), this third test confirms that the reduction of the $d$-current after the fault (Fig. 15b) provides a higher post-fault torque capability. This confirms the benefit $i$ ) listed in the introduction section.

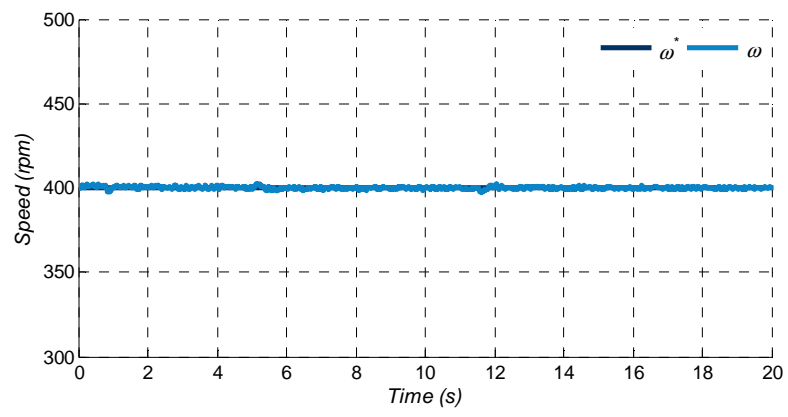

(a)

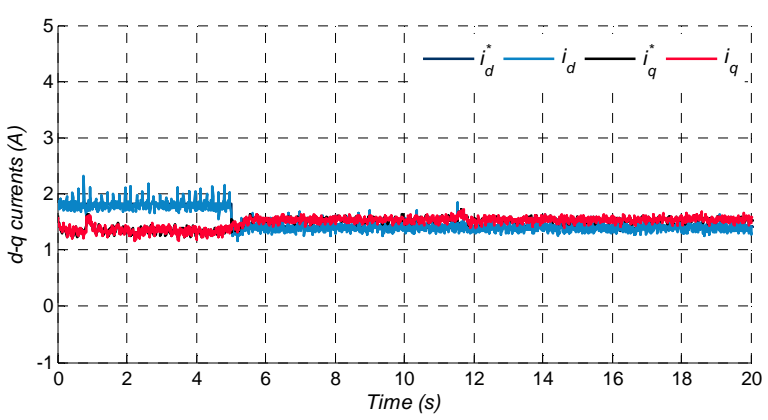

(b)

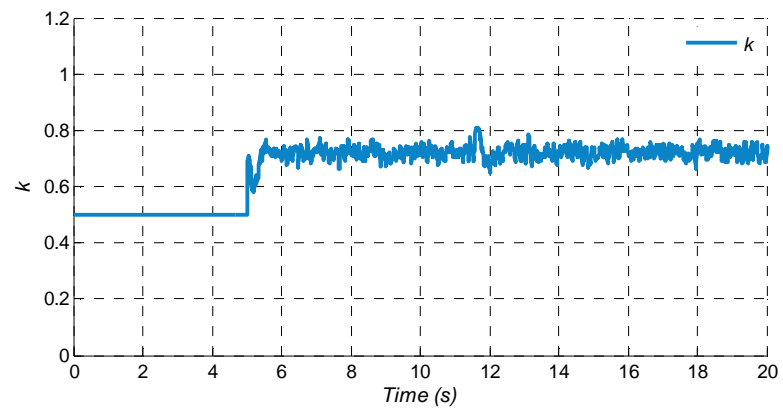

(c)

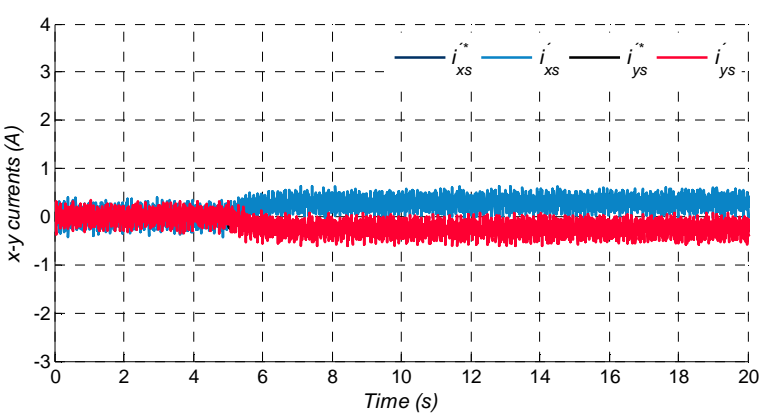

(d)

Fig. 10. Experimental results in a pre- to post-fault transition at 400 rpm with EIRFOC (switching frequency at $4 \mathrm{kHz}$ ). From top to bottom: motor speed, $\boldsymbol{d}-\boldsymbol{q}$ currents, imbalance degree $\boldsymbol{k}$ and $\boldsymbol{x}^{\prime}$ $\boldsymbol{y}^{\prime}$ currents. 


\section{IV.CONCLUSIONS}

The post-fault operation of multiphase drives is limited by fault restrictions that force the system to operate below rated values. Reducing the flux in such derated scenario can lead to improved efficiency at the expense of a lower dynamic response. Furthermore, overfluxing the machine after the fault occurrence brings undesirable consequences when parallel-connected converters are used, such as a lower torque/power productions or higher imbalance degrees in the current sharing. Instead of maintaining the pre-fault flux settings, it is shown in this work that the optimization of the post-fault flux using an offline LMC procedure improves the performance of the multiphase energy conversion system. Experimental results show that the efficient fault-tolerant control reduces the system losses and the degree of imbalance in the current sharing, allowing a higher torque/power production while retaining a good dynamic performance.

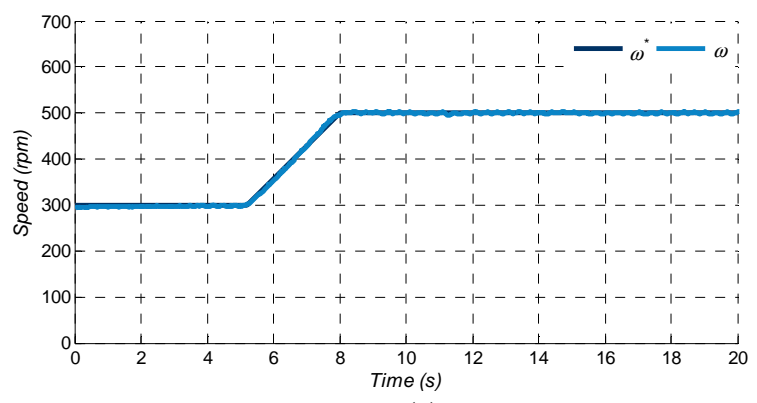

(a)

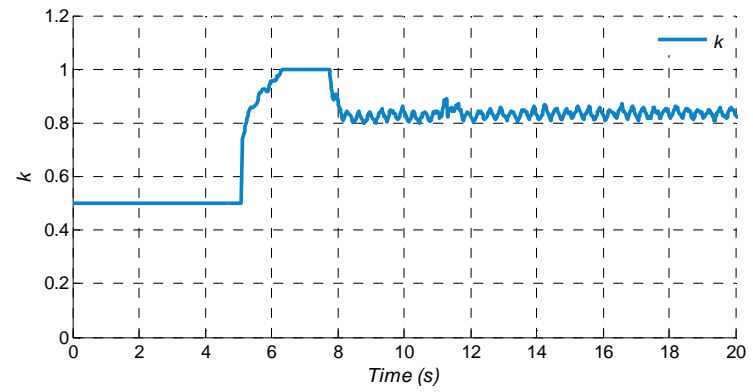

(c)

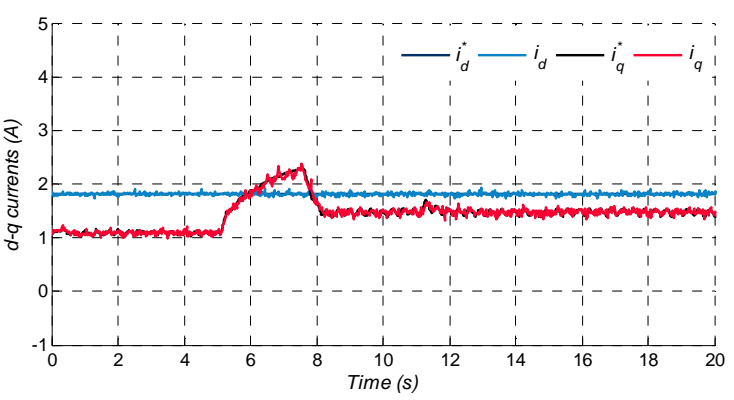

(b)

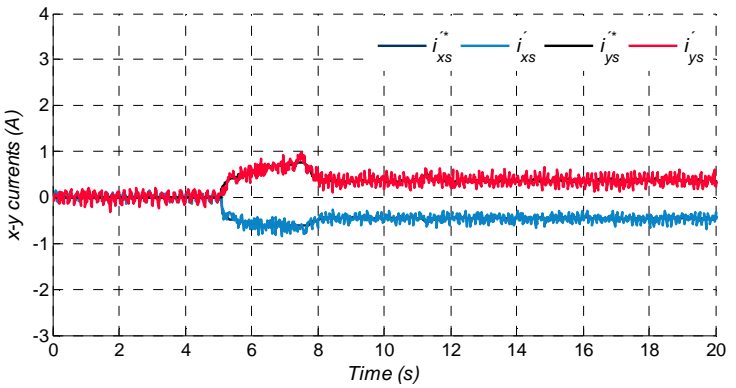

(d)

Fig. 11. Experimental results in a pre- to post-fault transition at with a speed change from 300 to 500 rpm (IRFOC). From left to right and from top to bottom: motor speed, $d-q$ currents, imbalance degree $k$ and $x^{\prime}-y^{\prime}$ currents

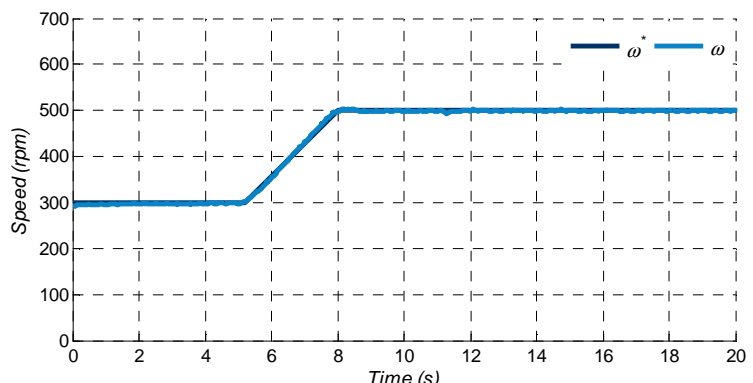

(a)

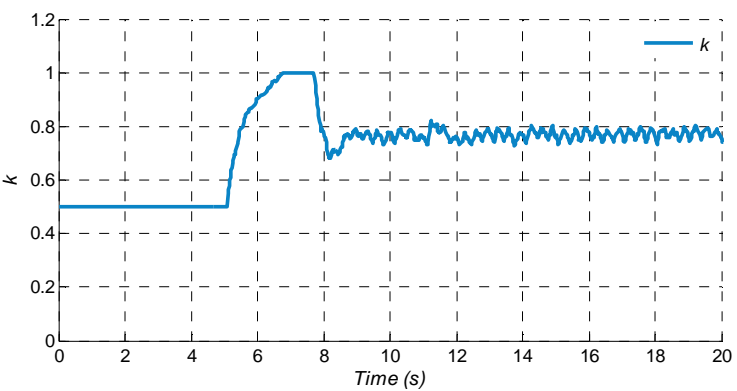

(c)

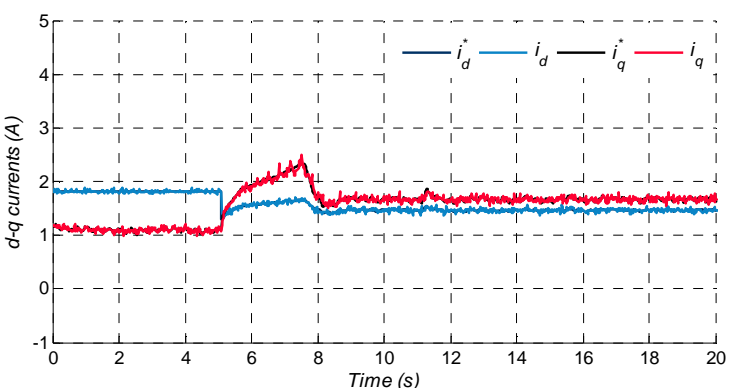

(b)

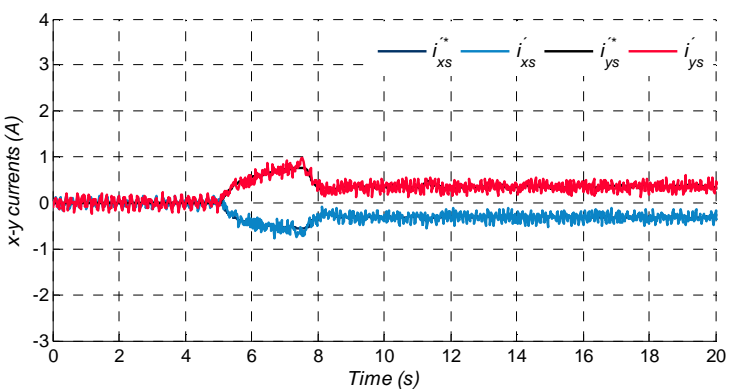

(d)

Fig. 12. Experimental results in a pre- to post-fault transition at with a speed change from 300 to 500 rpm (EIRFOC). From left to right and from top to bottom: motor speed, $\boldsymbol{d}-\boldsymbol{q}$ currents, imbalance degree $\boldsymbol{k}$ and $\boldsymbol{x}^{\prime}-\boldsymbol{y}^{\prime}$ currents. 


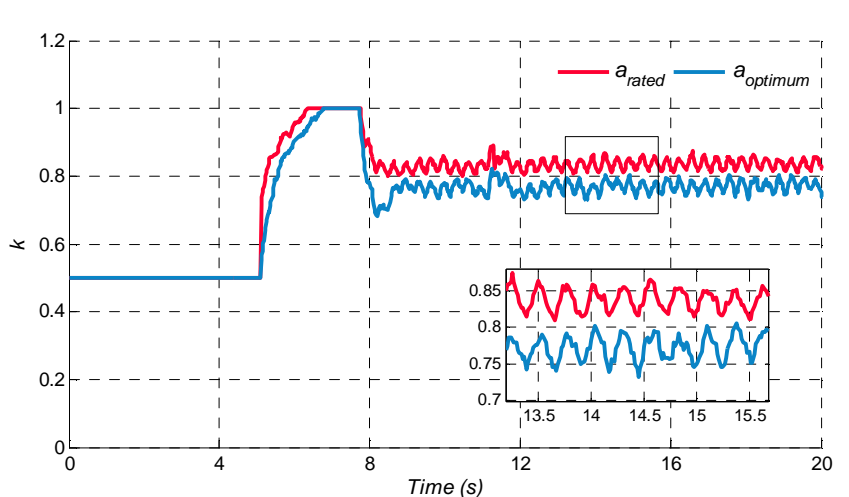

Fig. 13. Degree of imbalance $(k)$ in a pre- to post-fault transition with a speed change from 300 to $500 \mathrm{rpm}$. Result obtained using the IRFOC method is drawn in red trace while blue trace shows the system response using the EIRFOC technique.

\section{REFERENCES}

[1] E. Levi, "Advances in Converter Control and Innovative Exploitation of Additional Degrees of Freedom for Multiphase Machines," IEEE Trans. Ind. Electron., vol 63, no. 1, pp. 433-448, 2016.

[2] F. Barrero and M.J. Duran, "Recent Advances in the Design, Modeling and Control of Multiphase Machines - Part 1," IEEE Trans. Ind. Electron., vol 63, no. 1, pp. 449-458, 2016.

[3] M.J. Duran and F. Barrero, "Recent Advances in the Design, Modeling and Control of Multiphase Machines - Part 2," IEEE Trans. Ind. Electron., vol 63, no. 1, pp. 459-468, 2016.

[4] W. Cao, B.C. Mecrow, G.J. Atkinson, J.W. Bennett and D.J. Atkinson, "Overview of electric motor technologies used for more electric aircraft (MEA)" IEEE Trans. Ind. Electron., vol. 59, no. 9, pp. 3523-3531, 2012.

[5] V. Yaramasu, B. Wu, P.C. Sen, S. Kouro and M. Narimani, "High-power wind energy conversion systems: State-of-theart and emerging technologies," IEEE Trans. Ind. Electron., vol. 59, no. 9, pp. 3523-3531, 2012.

[6] H.S. Che, M.J. Duran, E. Levi, M. Jones, W.P. Hew and N.A. Rahim, "Postfault operation of an asymmetrical six-phase induction machine with single and two isolated neutral points," IEEE Trans. Power Electron., vol. 29, no. 10, pp. 5406-5416, 2014.

[7] I. Gonzalez, M.J. Duran, H.S. Che, E. Levi and J.A. Aguado, "Fault-tolerant efficient control of six-phase induction generators in wind energy conversion systems with seriesparallel machine-side converters," in Proc. of Power Electronics, Machines and Drives Conf. PEMD, Manchester, UK, CD-ROM, 2014.

[8] H. Guzman, M.J. Duran, F. Barrero, B. Bogado and S. Toral, "Speed control of five-phase induction motors with integrated open-phase fault operation using model-based predictive current control techniques," IEEE Trans. Ind. Electron., vol. 61, no. 9, pp. 4474-4484, 2014.

[9] H. Guzman, F. Barrero and M.J. Duran, "IGBT-gating failure effect on a fault-tolerant predictive current controlled 5-phase induction motor drive," IEEE Trans. on Industrial Electronics, vol. 62, no. 1, pp. 15-20, 2015.

[10] H. Guzman, M.J. Duran, F. Barrero, B. Bogado, I. GonzalezPrieto and M.R. Arahal, "Comparative Study of Predictive and Resonant Controllers in Fault-Tolerant Five-phase Induction Motor Drives," IEEE Trans. Ind. Electron., vol. 63, no. 1, pp. 606-617, 2016.

[11] M.J. Duran, I. Gonzalez-Prieto, M. Bermudez, F. Barrero, H. Guzman and M.R. Arahal, "Optimal Fault-tolerant Control of Six-phase Induction Motor Drives with Parallel Converters" IEEE Trans. Ind. Electron., vol. 63, no. 1, pp. 629-640, 2016.
[12] I. Gonzalez-Prieto, M.J. Duran, H.S. Che, E. Levi and F. Barrero "Fault-tolerant Operation of Six-phase Energy Conversion Systems with Parallel Machine-side Converters," IEEE Trans. Power Electron., vol. 31, no. 4, pp. 3068-3079, 2016.

[13] C. Thanga Raj, S. P. Srivastava, and P. Agarwal, "Energy efficient control of three-phase induction motor - a review," International Journal of Computer and Electrical Engineering, vol. 1, no. 1, pp. 61-71, 2009.

[14] A. Taheri, A. Rahmati and S. Kaboli, "Efficiency improvement in DTC of six-phase induction machine by adaptive gradient descent of flux," IEEE Trans. Power Electron., vol. 27, no. 3, pp. 1552-1562, 2012.

[15] D. S. Kirschen, D. W. Novotny, and T. A. Lipo, "Optimal efficiency control of an induction motor drive," IEEE Trans. Energy Convers., vol. 2, no. 1, pp. 70-76, 1987.

[16] A. Mesemanolis, C. Mademlis, and I. Kioskeridis, "High efficiency control for a wind energy conversion system with induction generator," IEEE Trans. Energy Convers., vol. 27, no. 4, pp. 958-967, 2012.

[17] M.G. Simoes, B.K. Bose, and J. Spiegel, "Fuzzy logic based intelligent control of a variable speed cage machine wind generation system," IEEE Trans. Power Electron., vol. 12, no. 1, pp. 87-95, 1997.

[18] B. K. Bose, N. R. Patel, and K. Rajashekara, "A neuro-fuzzybased on-line efficiency optimization control of a stator fluxoriented direct vector-controlled induction motor drive," IEEE Trans. Ind. Electron., vol. 44, no. 2, pp. 270-273, 1997.

[19] G.C.D Sousa, B.K. Bose and J.G. Cleland, "A fuzzy logic based on-line efficiency optimization control of an indirect vector-controlled induction motor drive," IEEE Trans. Ind. Electron., vol. 42, no. 2, pp. 192-198, 1995.

[20] G.K. Kim, I.J. Ha and M.S. Ko, "Control of induction motors for both high dynamic performance and high power efficiency", IEEE Trans. Ind. Appl., vol. 39, no. 4, pp. 323333, 1992.

[21] K. Takahashi, K. Ohishi and T. Kanmachi, "A new quickresponse and high-efficiency control strategy of an induction motor," IEEE Transactions Ind. Appl., vol. IA-22, no. 5, pp. 820-827, 1986.

[22] R.D Lorenz, and S.-M Yang, "Efficiency-optimized flux trajectories for closed-cycle operation of field-orientation induction machine drives," IEEE Trans. Ind. Appl., vol. 28, no. 3, pp. 574-580, 1992.

[23] S.K. Sul, and M.H. Park, "A novel technique for optimal efficiency control of a current-source inverter-fed induction motor," IEEE Trans. Power Electron., vol. 3, no. 2, pp. 192199, 1988.

[24] Q. Zengcai, M. Ranta, M. Hinkkanen, and J. Luomi, "Lossminimizing flux level control of induction motor drives," IEEE Trans. Ind. Appl., vol., 48, no. 2, pp., 952-961, 2012.

[25] F. Fernández-Bernal, A. García-Cerrada and R. Faure, "Model-based loss minimization for DC and AC vectorcontrolled motors including core saturation", IEEE Trans. Ind. Appl., vol. 36, no. 3, pp. 755-762, 2000.

[26] G.O. Garcia, J.C. Mendes, R.C. Stephan and E.H. Watanabe, "An efficient controller for an adjustable speed induction motor drive,"," IEEE Trans. Ind. Electron., vol. 41, no. 5, pp. 533-539, 1994.

[27] E. Jung, H. Yoo, S. Sul, H. Choi, and Y. Choi, "A nine-phase permanent-magnet motor drive system for an ultrahigh-speed elevator," IEEE Trans. Ind. Appl., vol. 48, no. 3, pp. 987-995, 2012.

[28] "Gamesa 5.0 MW" Gamesa Technological Corporation S.A., 2014.Online http://www.gamesacorp.com/recursos/doc/ productosservicios/aerogeneradores/catalogo-g10x-45mw.pdf 


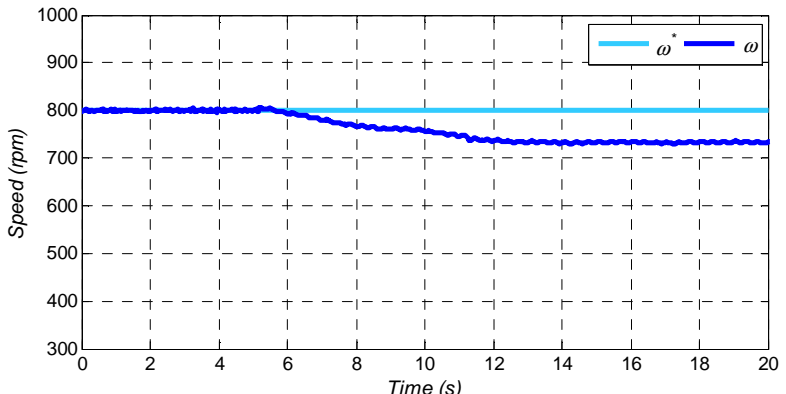

(a)

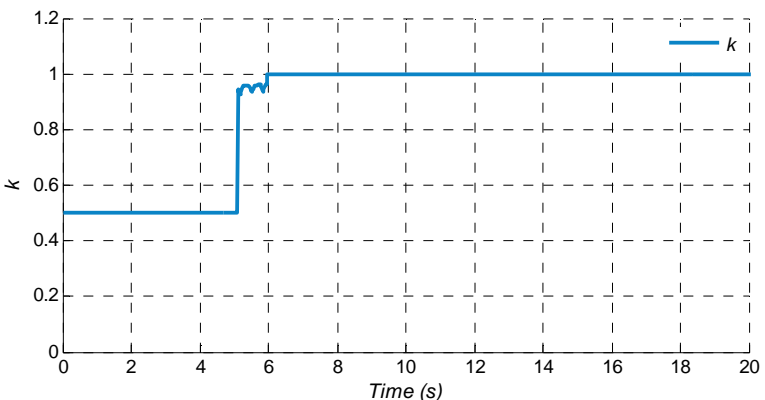

(c)

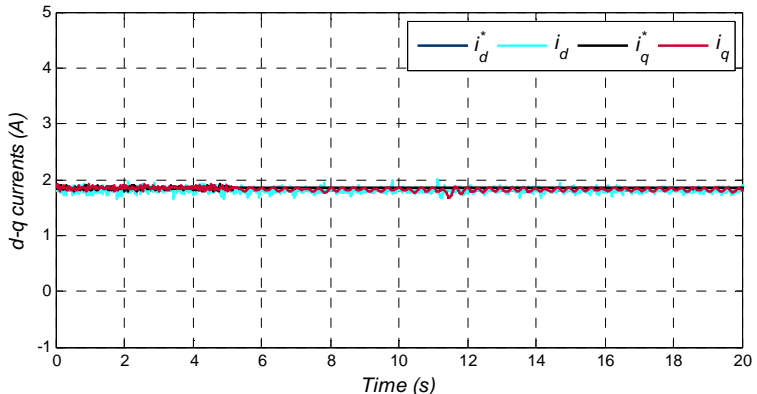

(b)

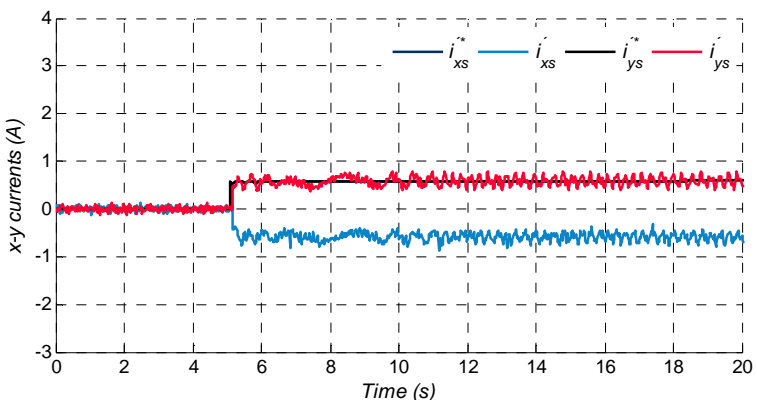

(d)

Fig. 14. Experimental results in a pre- to post-fault transition at $800 \mathrm{rpm}$ with IRFOC. From left to right and from top to bottom: motor speed, $\boldsymbol{d}-\boldsymbol{q}$ currents, imbalance degree $\boldsymbol{k}$ and $\boldsymbol{x}^{\prime}-\boldsymbol{y}^{\prime}$ currents.

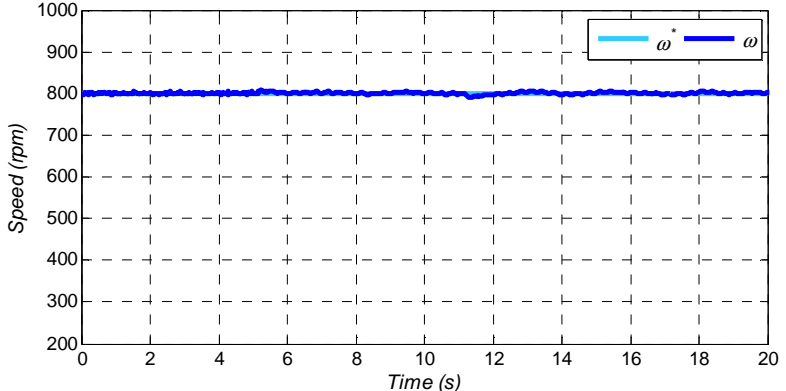

(a)

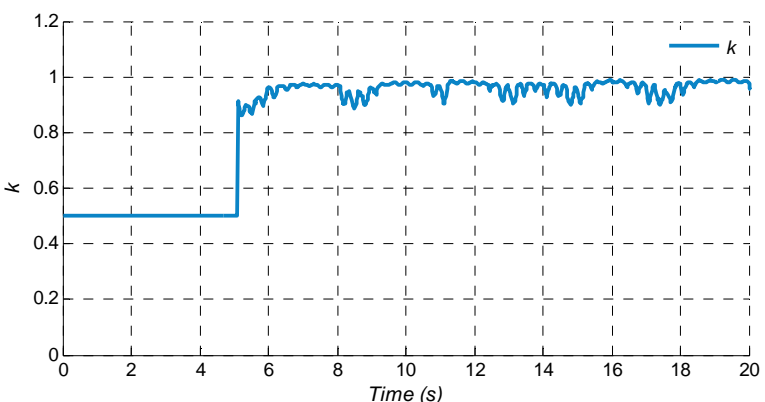

(c)

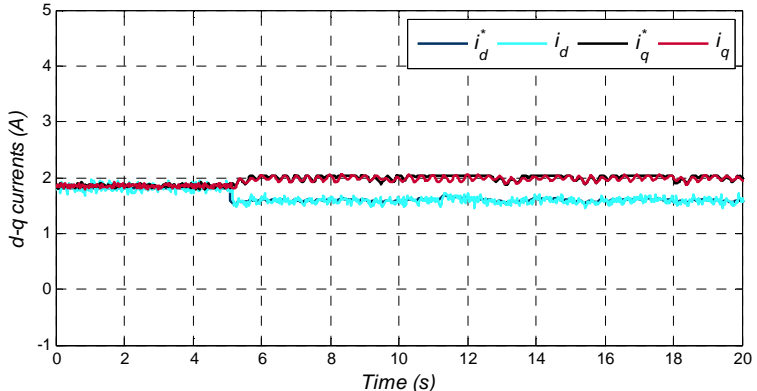

(b)

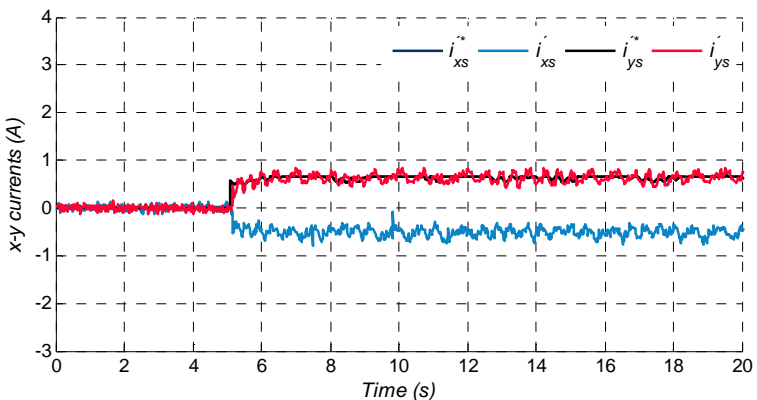

(d)

Fig. 15. Experimental results in a pre- to post-fault transition at $800 \mathrm{rpm}$ with EIRFOC. From left to right and from top to bottom: motor speed, $\boldsymbol{d}-\boldsymbol{q}$ currents, imbalance degree $\boldsymbol{k}$ and $\boldsymbol{x}^{\prime}-\boldsymbol{y}^{\prime}$ currents. 
[29] C. Ditmanson, P. Hein, S. Kolb, J. Mölck, and S. Bernet, "A new modular flux-switching permanent-magnet drive for large wind turbines," IEEE Trans. Ind. Appl., vol. 50, no. 6, pp. 3787-3794, 2014.

[30] H.S. Che, E. Levi, M. Jones, M.J. Duran, W.P. Hew, and N.A. Rahim, "Operation of a six-phase induction machine using series-connected machine-side converters," IEEE Trans. Ind. Electron., vol. 61, no. 1, pp. 164-176, 2014.

[31] S.S. Gjerde, P.K. Olsen, K. Ljokelsoy, and T.M. Undeland, "Control and fault handling in a modular series-connected converter for a transformerless $100 \mathrm{kV}$ low-weight offshore wind turbine," IEEE Trans. Ind. Appl., vol. 50, no. 2, pp. 1094-1105, 2014.

[32] H.S. Che, W.P. Hew, N.A. Rahim, E. Levi, M. Jones, and M.J. Duran, "A six-phase wind energy induction generator system with series-connected DC-links," in Proc. IEEE Power Electr. for Distributed Generation Systems PEDG, pp. 26-33, 2012.

[33] Y. Zhao and T.A. Lipo, "Space vector PWM control of dual three-phase induction machine using vector space decomposition," IEEE Trans. Ind. Appl., vol. 31, no. 5, pp. 1100-1109, 1995.

[34] B. Wu, Y. Lang, N. Zargari, and S. Kouro, "Power conversion and control of wind energy systems," IEEE Press - John Wiley and Sons, Hoboken, NJ, 2011.

[35] S. Yang, A. Bryant, P. Mawby, D. Xiang, L. Ran, and P. Tavner, "An industry-based survey of reliability in power electronic converters," IEEE Trans. Ind. Appl., vol. 47, no. 3, pp. 1441-1451, Jun. 2011.

[36] B. Lu and S. Sharma, "A literature review of IGBT fault diagnostic and protection methods for power inverters," IEEE Trans. Ind. Appl., vol. 45, no. 5, pp. 1770-1777, Oct. 2009.

[37] M. Salehifar, R.S. Arashloo, J.M. Moreno-Equilaz, V. Sala and L. Romeral, "Fault detection and fault tolerant operation of a five phase PM motor drive using adaptive model identification approach," IEEE Trans. Emerg. Sel. Topics Power Electron., vol. 2, no.2, pp. 212-223, 2014.

[38] U. Choi, J.S. Lee, F. Blaabjerg and K.B. Lee "Open-Circuit Fault Diagnosis and Fault-Tolerant Control for a GridConnected NPC Inverter," IEEE Trans. Power Electron., Early Access, 2015.

[39] N.K. Nguyen, F. Meinguet, E. Semail and X. Kestelyn"FaultTolerant Operation of an Open-End Winding Five-Phase PMSM Drive With Short-Circuit Inverter Fault," IEEE Trans. Ind. Electron., vol. 63, no. 1, pp. 595-605, 2016.

[40] B.Sen and J. Wang "Stationary Frame Fault Tolerant Current Control of Poly-phase Permanent Magnet Machines under Open-Circuit and Short-Circuit Faults," IEEE Trans. Power Electron., Early Access, 2015.

[41] L. Alberti and N. Bianchi, "Experimental tests of dual threephase induction motor under faulty operating condition," IEEE Trans. Ind. Electron., vol. 59, no. 5, pp. 2041-2048, 2012.

[42] GAMS web, “A User's Guide”, Available: http://gams.com/docs/

[43] H.S. Che, E. Levi, M. Jones, W.P. Hew, and N.A. Rahim, "Current control methods for an asymmetrical six-phase induction motor drive", IEEE Trans. Power Electron., vol. 29, no. 10, pp. 5406-5416, 2014.

[44] A. Yepes, J.A. Riveros, J. Doval-Gandoy, F. Barrero, O. Lopez, B. Bogado, M. Jones, E. Levi, "Parameter Identification of Multiphase Induction Machines with Distributed Windings-Part 1: Sinusoidal Excitation Methods," IEEE Trans. Energy Convers., vol. 27, no. 4, pp. 1056-1066, 2012.
[45] J.A. Riveros, A. Yepes, F. Barrero, J. Doval-Gandoy, B. Bogado, O. Lopez, M. Jones, E. Levi, "Parameter Identification of Multiphase Induction Machines with Distributed Windings-Part 2: Time-Domain Techniques," IEEE Trans. Energy Convers., vol. 27, no. 4, pp. 1067-1077, 2012.

[46] J. Yun, J. Cho, S. B. Lee, and J. Yoo, "On-line detection of high-resistance connections in the incoming electrical circuit for induction motors," IEEE Trans. Ind. Appl., vol. 45, no. 2, pp. 694-702, Mar./Apr. 2009.

[47] J. Hang, J. Zhang and M. Cheng "Detection and Discrimination of Open Phase Fault in Permanent Magnet Synchronous Motor Drive System," IEEE Trans. Power Electron., Early Access, 2015.

[48] L. Zarri, M. Mengoni, Y. Gritli, A. Tani, F. Filipetti, G. Serra and D. Casadei "Detection and Localization of Stator Resistance Dissymmetry Based on Multiple Reference Frame Controllers in Multiphase Induction Motor Drives," IEEE Trans. Ind. Electron., vol. 60, no. 8, pp. 3506-3518, 2013.

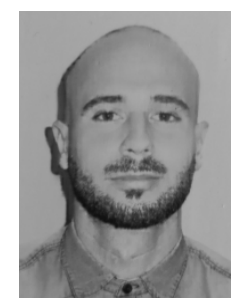

Ignacio Gonzalez Prieto was born in Malaga, Spain, in 1987. He received the Industrial Engineer and M. Sc. degrees from the University of Malaga, Spain, in 2012 and 2013, respectively. He obtained the PhD degree in Electronic Engineering from the University of Seville, Spain, in 2016. His research interests include multiphase machines, wind energy systems and electrical vehicles.

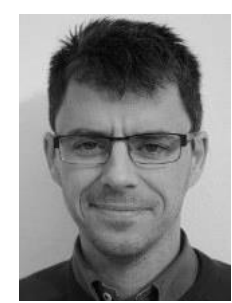

Mario J. Duran was born in Bilbao, Spain, in 1975 He received the M.Sc. and Ph.D. degrees in Electrical Engineering from the University of Málaga Spain, in 1999 and 2003, respectively. He is currently an Associate Professor with the Department of Electrical Engineering at the University of Málaga. His research interests include modeling and control of multiphase drives and renewable energies conversion systems.

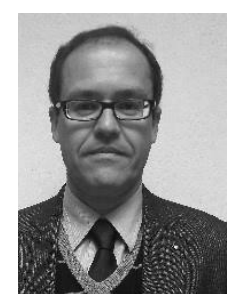

Federico Barrero (M 04; SM 05) received the MSc and $\mathrm{PhD}$ degrees in Electrical and Electronic Engineering from the University of Seville, Spain, in 1992 and 1998, respectively. In 1992, he joined the Electronic Engineering Department at the University of Seville, where he is currently an Associate Professor. He received the Best Paper Awards from the IEEE Trans. on Ind. Electron. for 2009 and from the IET Electric Power Applications for 2010-2011.

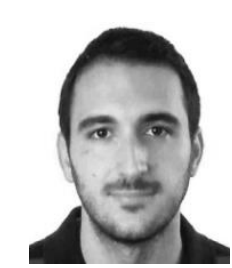

Mario Bermudez was born in Málaga, Spain, in 1987. He received the Industrial Engineer degree from University of Málaga, Spain, in 2014. Currently, he is working toward the Ph.D. degree in the Laboratory of Electrical Engineering and Power Electronics of Lille (L2EP), Arts et Métiers ParisTech, Lille, France, and in the Electronic Engineering Department of the University of Seville, Spain. His current research interests include modeling and control of multiphase drives, DSP-based systems and electrical vehicles.

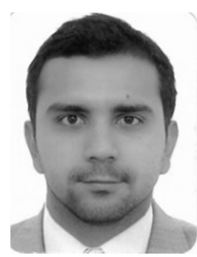

Hugo Guzman received the B.Eng. (2009), MSc (2011) and $\mathrm{PhD}$ (2015) degrees in Electronic and Mechatronic Engineering from the Pontificia Universidad Javeriana (Bogota-Colombia), the University of Seville (Seville-Spain) and the University of Malaga (Malaga-Spain), respectively. Dr. Guzman worked in AICIA (2007-2010) and the University of Seville, Electronic Engineering Department (2010-2012), as a research assistant, participating in several power electronics R\&D projects (Seville-Spain). He then joined the University of Malaga, Electrical Engineering Department (2012-2015), as a researcher funded by an Andalucia Tech scholarship (Malaga-Spain). 